\title{
A NOVEL CARBAPENEM ANTIBIOTIC, SM-7338 STRUCTURE-ACTIVITY RELATIONSHIPS
}

\author{
Makoto Sunagawa, Haruki Matsumura, Takaaki Inoue, \\ Masatomo Fukasawa and Masuhiro Kato
}

\author{
Research Laboratories, Sumitomo Pharmaceuticals Co., Ltd., \\ 3-1-98 Konohana-ku, Osaka 554, Japan
}

(Received for publication October 11, 1989)

\begin{abstract}
A series of new carbapenem compounds, which have a pyrrolidin-3'-ylthio group substituted with various aminocarbonyl group at $\mathrm{C}-5^{\prime}$ position as $\mathrm{C}-2$ side chain, have been prepared. The antibacterial activity and the stability to renal dehydropeptidase-I of these compounds were investigated, and the structure-activity relationships were discussed. In this series, SM-7338; $(1 R, 5 S, 6 S)$-2-[( $3 S, 5 S)$-5-dimethylaminocarbonylpyrrolidin-3-ylthio]-6-[( $R)$-1-hydroxyethyl]1-methylcarbapen-2-em-3-carboxylic acid (5a) was the most interesting compound.
\end{abstract}

Thienamycin and the related naturally occurring compounds are $\beta$-lactam antibiotics possessing potent antibacterial activities against a wide range of Gram-positive and Gram-negative bacteria. But they are chemically unstable and easily metabolized by renal dehydropeptidase-I (DHP-I ${ }^{1,2)}$. Therefore, extensive efforts have been directed toward the synthesis of new carbapenem compounds in order to improve these disadvantageous properties.

We have studied on the synthesis of a variety of carbapenem derivatives and found that the carbapenem compounds having 5 '-aminocarbonyl pyrrolidin-3'-ylthio group as C-2 side chain showed good antibacterial activities. We have also investigated the correlation of biological properties with the structure focusing on (1) the stereochemistry at the asymmetric centers (C-3' and C-5') in the C-2 side chain, (2) the substituents $R_{1}$ and $R_{2}$ on the aminocarbonyl group $\left(C O N R_{1} R_{2}\right)$, and (3) the introduction of methyl group at the $\mathrm{C}-1$ position of carbapenem skeleton in the series of 2-(5'-amino-carbonylpyrrolidin-3'-ylthio)-carbapenem derivatives. As a result, we ultimately obtained a novel carbapenem, $(1 R, 5 S, 6 S)-2-[(3 S, 5 S)-5-$ dimethylaminocarbonylpyrrolidin-3-ylthio]-6-[(R)-1-hydroxyethyl]-1-methylcarbapen-2-em-3-carboxylic acid (SM-7338) ${ }^{3)}$, which exhibited a well balanced antibacterial spectrum including antipseudomonal activity and high stability to DHP-I.

\section{Chemistry}

4-Mercaptopyrrolidine derivatives were prepared by a sequence of reactions shown in Scheme 1. trans-4-Hydroxy-L-proline (7) was treated with $p$-nitrobenzyl chloroformate to give $N$-protected

Fig. 1. Structures of thienamycin and SM-7338.<smiles>CC(O)[C@H]1C(=O)N2C(C(=O)O)=C(SCCN)C[C@H]12</smiles>

Thienamycin<smiles>CC(=O)[C@@H]1C[C@@H](SC2=C(C(=O)O)N3C(=O)[C@H](C(C)O)[C@H]3[C@H]2C)CN1</smiles>

SM-7338 (59) 
Scheme 1.

(1)<smiles>O=C(O)C1CC(O)CN1</smiles>

7

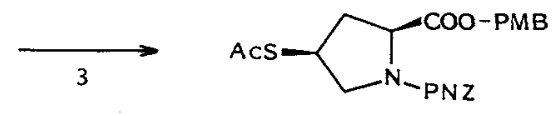

10

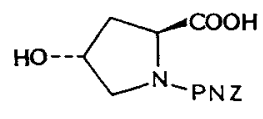

8

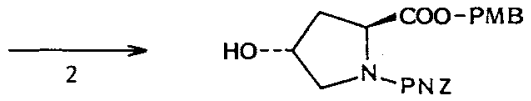

9

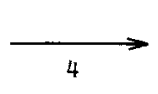<smiles>CCCNC(=O)[C@@H]1CC(S)CN1[N+](=O)[O-]</smiles>

13

(2)<smiles>[Y20]N1C[C@H](C=O)C[C@H]1C(=O)O[Na]</smiles>

14

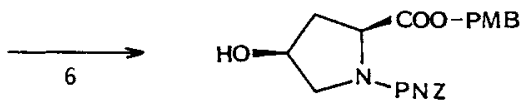

15

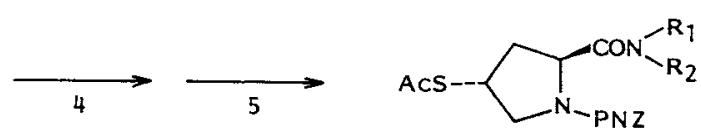

16

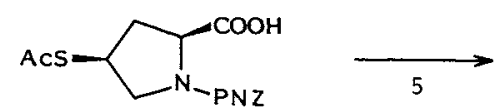

11<smiles>[R2]NC(=O)[C@@H]1C[C@H](S)CN1[R2]</smiles>

12

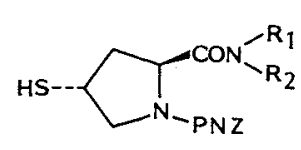

17

(3)

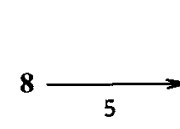<smiles>[R2]N([R2])C(=O)C1CC(O)CN1P([R1])[R]</smiles>

18<smiles>[R2]NC(=O)[C@@H]1C[C@H](O[Na])CN1[N+]([R1])=O</smiles>

19

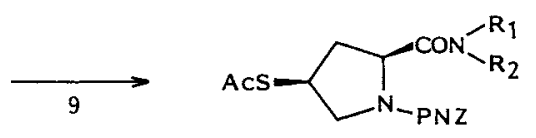

12

1: $\mathrm{PNZ}-\mathrm{Cl}, \mathrm{NaOH}, 2: \mathrm{PMB}-\mathrm{Cl}, \mathrm{NEt}_{3}, 3:=(\mathrm{NCOOEt})_{2}, \mathrm{PPh}_{3}, \mathrm{AcOH}$, 4: TFA, anisole, 5: $\mathrm{ClCOO} i$-Pr, $\mathrm{NEt}_{3}, \mathrm{HNR}_{1} \mathrm{R}_{2}, 6: \mathrm{NaOH}, 7:=(\mathrm{NCOOEt})_{2}, \mathrm{PPh}_{3}, \mathrm{HCOOH}, 8: \mathrm{MsCl}, \mathrm{NEt}_{3}, 9: \mathrm{AcSK}$.<smiles>O=C(O)C1CC(O)CN1</smiles>

20

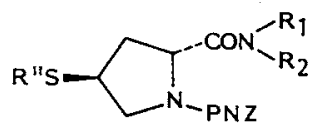

$21 \mathrm{R}^{\prime \prime}=\mathrm{Ac}$

$22 \mathrm{R}^{\prime \prime}=\mathrm{H}$

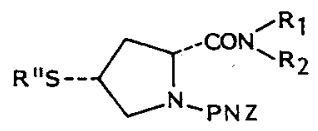

$23 \mathrm{R}^{\prime \prime}=\mathrm{Ac}$

$24 \mathrm{R}^{\prime \prime}=\mathrm{H}$ 
4-hydroxyproline (8), which was esterified with $p$-methoxybenzyl chloride in the presence of triethylamine to give $p$-methoxybenzyl ester (9). Conversion of hydroxyl group of 9 to acetylthio group was carried out with thioacetic acid by Mitsunobu reaction ${ }^{4)}$ to give thioacetate (10) with inversion of C-4 configuration. Removal of $p$-methyoxybenzyl (PMB) protecting group of $\mathbf{1 0}$ by the treatment with trifluoroacetic acid and anisole ${ }^{5)}$ gave carboxylic acid (11), which was transformed into amide (12) by activation with isopropyl chloroformate followed by reaction with the corresponding amines. Finally the acetylthio group of $\mathbf{1 2}$ was readily hydrolyzed with $4 \mathrm{~N} \mathrm{NaOH}$ in methanol to give mercaptan (13), which was used in the next reaction without purification.

The preparation of the C-4 epimer of $\mathbf{1 3}$ was achieved by the inversion of hydroxyl group of $\mathbf{9}$ using Mitsunobu reaction ${ }^{4)}$ followed by the method described above.

Some of the mercaptans were also prepared by the different synthetic route as shown in Scheme 1 . Thus, 8 was transformed into amide (18) by similar procedure to that described above. The hydroxyl group of 18 was mesylated with methanesulfonyl chloride and triethylamine to give mesylate (19). Treatment of 19 with potassium thioacetate ${ }^{6}$ in DMF and toluene gave thioacetate (12), which was hydrolyzed to give 13.

The antipode and C-2 epimer of $\mathbf{1 3}$ could be obtained by using cis-4-hydroxy-D-proline (20) as a starting material under the similar reaction condition to those described above.

The preparation of a series of carbapenems was achieved according to an established method by Merck's group ${ }^{7)}$. The general synthetic pathway is shown in Scheme 2. The chiral 2-oxo-carbapenam ester $(25)^{8)}$ was used as the starting material for the synthesis of all carbapenem compounds. Treatment of 25 with diphenyl chlorophosphate in the presence of diisopropylethylamine, followed by addition of

Scheme 2

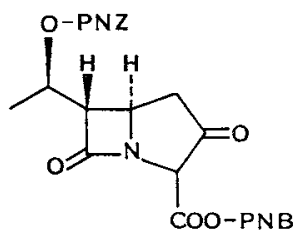

25

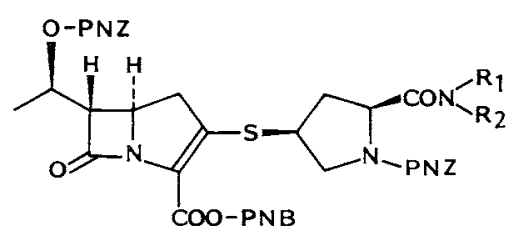

26

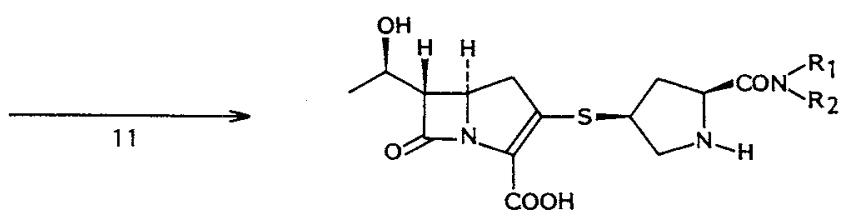

1

10: $(\mathrm{PhO})_{2} \mathrm{POCl}, i-\mathrm{Pr}_{2}$ EtN, 13, 11: $\mathrm{H}_{2}-\mathrm{Pd}-\mathrm{C}$.

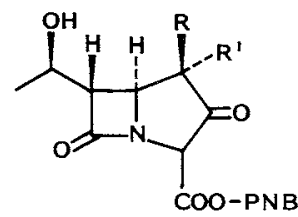

$27 \mathrm{R}=\mathrm{CH}_{3} \quad \mathrm{R}^{\prime}=\mathrm{H}$

$28 \mathrm{R}=\mathrm{H} \quad \mathrm{R}^{\prime}=\mathrm{CH}_{3}$ 
(2S,4S)-4-mercaptoproline derivatives (13) provided carbapenem esters (26). Removal of $p$-nitrobenzyl (PNB) and $p$-nitrobenzyloxycarbonyl (PNZ) protecting groups was carried out by catalytic hydrogenation of 26 over $10 \%$ Pd-C in the presence of 3-( $N$-morpholino)propanesulfonic acid (MOPS) buffer ( $\mathrm{pH} \mathrm{7.0)}$ provided the target carbapenem compounds having $\left(3^{\prime} S, 5^{\prime} S\right)$-C-2 side chain (1), after purification by column chromatography on Diaion CHP-20P.

$\left(3^{\prime} R, 5^{\prime} S\right),\left(3^{\prime \prime} R, 5^{\prime} R\right)$ and $\left(3^{\prime} S, 5^{\prime} R\right)$-carbapenems, stereoisomers on the $C-2$ side chain $(2,3$ and 4$)$ were prepared similarly using mercaptans $(17,22$ and 24$)$ in place of 13.

As to the preparation of 1 -methyl analogues, $1 \beta$-methyl-2-oxocarbapenam (27) and $1 \alpha$-methyl isomer (28) were used as starting materials instead of 25. Syntheses of both intermediates have been previously reported ${ }^{9,10)}$. Convertion of 27 to $1 \beta$-methylcarbapenem (5) was carried out by similar procedure to that

Fig. 2. Carbapenem compounds have $5^{\prime}$-substituted pyrrolidinylthio side chain.

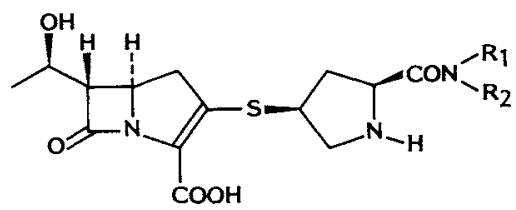

$$
\begin{array}{llll}
\text { 1a } & \mathrm{R}_{1}=\mathrm{R}_{2}=\mathrm{CH}_{3} & \text { 1g } & \mathrm{R}_{1}, \mathrm{R}_{2}=-\mathrm{CH}_{2} \mathrm{CH}=\mathrm{CHCH}_{2}- \\
\text { 1b } & \mathrm{R}_{1}=\mathrm{R}_{2}=\mathrm{H} & \text { lh } & \mathrm{R}_{1}=\mathrm{CH}_{3} \mathrm{R}_{2}=\mathrm{CH}_{2} \mathrm{CH}_{2} \mathrm{OH} \\
\text { 1c } & \mathrm{R}_{1}=\mathrm{CH}_{3} \quad \mathrm{R}_{2}=\mathrm{Bu} & & \\
\text { 1d } & \mathrm{R}_{1}, \mathrm{R}_{2}=-\left(\mathrm{CH}_{2}\right)_{3}- & \text { li } & \mathrm{R}_{1}=\mathrm{H} \quad \mathrm{R}_{2}=- \\
\text { le } & \mathrm{R}_{1}, \mathrm{R}_{2}=-\left(\mathrm{CH}_{2}\right)_{4}- & & \\
\text { 1f } & \mathrm{R}_{1}, \mathrm{R}_{2}=-\left(\mathrm{CH}_{2}\right)_{5}- & \text { lj } & \mathrm{R}_{1}=\mathrm{CH}_{3} \mathrm{R}_{2}=\mathrm{CH}_{2} \mathrm{CONHCH}_{3} \\
& & \text { lk } & \mathrm{R}_{1}=\mathrm{H} \quad \mathrm{R}_{2}=\mathrm{CH}_{2} \mathrm{CONHCH}_{3}
\end{array}
$$

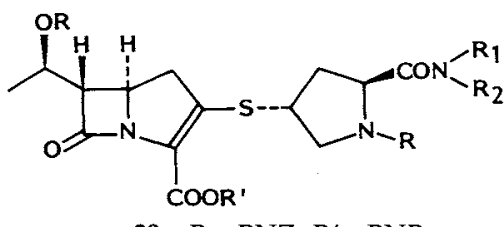

$29 \mathrm{R}=\mathrm{PNZ} \mathrm{R}^{\prime}=\mathrm{PNB}$

$2 \mathrm{R}=\mathrm{R}^{\prime}=\mathrm{H}$<smiles>[R2]NC(=O)C1CC(SC2=C(C([R20])=O)N3C(=O)[C@@H]([C@@H](C)O[R2])[C@H]3C2)CN1[R]</smiles>

$30 \quad \mathrm{R}=\mathrm{PNZ} \quad \mathrm{R}^{\prime}=\mathrm{PNB}$

$3 \quad \mathbf{R}=\mathbf{R}^{\prime}=\mathrm{H}$<smiles>[R][R](=[R])[R]([R])([R])[R]</smiles>

Fig. 3. 1-Methylcarbapenem compounds.<smiles>[R2]CNC(=O)[C@@H]1C[C@@H](SC2=C(C(=O)O[R])N3C(=O)[C@@H]([C@@H](C)O)[C@H]3[C@H]2C)CN1[R]</smiles>

$32 \mathrm{R}=\mathrm{PNZ} \quad \mathrm{R}^{\prime}=\mathrm{PNB}$

$5 \quad \mathrm{R}=\mathrm{R}^{\prime}=\mathrm{H}$<smiles>[R2]NC(=O)[C@H]1C[C@@H](SC2=C(C(=O)O[R2])N3C(=O)[C@@H]([C@@H](C)O)[C@H]3C2C)CN1[R]</smiles>

$33 \mathrm{R}=\mathrm{PNZ} \quad \mathrm{R}^{\prime}=\mathrm{PNB}$

$6 \mathrm{R}=\mathrm{R}^{\prime}=\mathrm{H}$ 
described above, but 28 could not be readily transformed to $1 \alpha$-methyl enolphosphate, as already reported ${ }^{10}$. Addition of a catalytic amount of 4-dimethylaminopyridine could lead to the completion of this transformation, and the enolphosphate was converted to $1 \alpha$-methylcarbapenem (6) by condensation reaction with mercaptan (13) and catalytic hydrogenation.

\section{Biological Properties}

The MICs of the novel carbapenems against Gram-positive and Gram-negative bacteria and the stability data $\left(\mathrm{T}_{1 / 2}\right)$ to DHP-I are listed in Tables 1, 2 and 3.

First of all, the effects of the stereochemistry at $\mathrm{C}^{\prime} 3^{\prime}$ and $\mathrm{C}-5^{\prime}$ positions on the $\mathrm{C}-2$ side chain moiety were investigated in 5'-carbamoyl and 5'-dimethylaminocarbonyl series (1a, 1b, 2a, 2b, 3a, 3b, $\mathbf{4 a}$ and $\mathbf{4 b})$. As shown in Table 1, all four stereoisomers showed excellent antibacterial activities against Gram-positive and Gram-negative bacteria except for Pseudomonas aeruginosa. There was remarkable difference in their observed anti-pseudomonal activities. cis-Isomers were more active than trans-isomers, and $\left(3^{\prime} S, 5^{\prime} S\right)$ isomers ( $\mathbf{1 a}$ and $\mathbf{1 b})$ showed the best anti-pseudomonal activity. Concerning the stability to DHP-I, significant difference was not found among four isomers in both cases of $\mathrm{CONH}_{2}$ and $\mathrm{CON}\left(\mathrm{CH}_{3}\right)_{2}$.

The correlation of biological activities with a variety of 5 -aminocarbonyl substituents $\left(\mathrm{CONR}_{1} \mathrm{R}_{2}\right)$ was investigated using the $\left(3^{\prime} S, 5^{\prime} S\right)$-stereoisomer, which was the most preferable isomer for anti-pseudomonal activity described above. In this series, all of the compounds synthesized showed excellent antibacterial activities against Gram-positive and Gram-negative bacteria tested. But a wide range of anti-pseudomonal activity $(0.78 \sim 25 \mu \mathrm{g} / \mathrm{ml})$ was also observed. The $5^{\prime}$-aminocarbonyl substituents, as well as the stereochemistry on $\mathrm{C}^{-} 3^{\prime}$ and $\mathrm{C}-5^{\prime}$, plays an important role for anti-pseudomonal activity. 1a, 1e and $1 \mathrm{~g}$ exhibited well balanced antibacterial spectra. The stability to DHP-I was not strongly influenced by variation of $R_{1}$ and $R_{2}$ (see Table 2).

Finally, the effects of introduction of methyl group at the $\mathrm{C}-1$ position of $\left(3^{\prime} S, 5^{\prime} S\right)-5^{\prime}-$

Table 1. Antibacterial activity and DHP-I stability of carbapenem compounds having 5'-substituted pyrrolidinylthio side chain (effect of stereochemistry of $\mathrm{C}-2$ side chain).

\begin{tabular}{|c|c|c|c|c|c|c|c|c|}
\hline \multirow{2}{*}{ Organism } & \multicolumn{8}{|c|}{$\operatorname{MIC}(\mu \mathrm{g} / \mathrm{ml})$} \\
\hline & $\mathbf{l b}$ & $\mathbf{2 b}$ & $3 \mathbf{b}$ & $4 b$ & $\mathbf{1 a}$ & $2 \mathbf{a}$ & $3 \mathbf{a}$ & $\mathbf{4 a}$ \\
\hline S.a. FDA 209P & $\leq 0.013$ & $\leq 0.013$ & $\leq 0.013$ & 0.025 & $\leq 0.013$ & $\leq 0.013$ & 0.025 & $\leq 0.013$ \\
\hline S.p. Cook & $\leq 0.013$ & N.D. & $\leq 0.013$ & $\leq 0.013$ & $\leq 0.013$ & $\leq 0.013$ & $\leq 0.013$ & $\leq 0013$ \\
\hline E.c. NIHJ JC-2 & $\leq 0.013$ & 0.05 & $\leq 0.013$ & 0.39 & $\leq 0.013$ & 0.10 & 0.05 & 0.05 \\
\hline K.p. ATCC 10031 & $\leq 0.013$ & 0.025 & $\leq 0.013$ & $\leq 0.013$ & $\leq 0.013$ & 0.10 & 0.025 & 0.025 \\
\hline P.m. GN 2425 & 0.05 & 0.20 & 0.10 & 0.05 & 0.10 & 0.78 & 0.39 & 0.20 \\
\hline P.a. IFO 3451 & 1.56 & 25 & 6.25 & 12.5 & 0.78 & 50 & 3.13 & $>25$ \\
\hline S.m. X 100 & 0.05 & 0.10 & 0.05 & 0.05 & 0.05 & 0.39 & 0.10 & 0.10 \\
\hline E.c. ML $1410 / \mathrm{RP}^{\mathrm{a}}$ & 0.05 & 0.20 & 0.05 & 0.10 & 0.05 & 0.78 & 0.20 & 0.10 \\
\hline E.c. GN $5482^{\mathrm{a}}$ & $\leq 0.013$ & 0.05 & $\leq 0.013$ & 0.025 & $\leq 0.013$ & 0.20 & 0.05 & 0.05 \\
\hline P.v. GN $7919^{\mathrm{a}}$ & 0.10 & 0.20 & 0.05 & 0.10 & 0.10 & 1.56 & 0.78 & 0.39 \\
\hline S.m. GN $6473^{\mathrm{a}}$ & 0.10 & 0.10 & 0.05 & 0.10 & 0.10 & 1.56 & 0.78 & 0.39 \\
\hline DHP-I ${ }^{\mathrm{b}} \mathrm{T}_{1 / 2}$ (minutes) & 22 & 16 & 19 & 15 & 16 & 21 & 45 & 57 \\
\hline
\end{tabular}

a $\beta$-Lactamase-producing strain.

- Partially purified renal DHP-I of swine.

Abbreviations: S.a., Staphylococcus aureus; S.p., Streptococcus pyogenes; E.c., Escherichia coli; K.p., Klebsiella pneumoniae; P.m., Proteus mirabilis; P.a., Pseudomonas aeruginosa; S.m., Serratia marcescens; P. v., Proteus vulgaris.

N.D.: Not determined. 
Table 2. Antibacterial activity and DHP-I stability of carbapenem compounds having 5'-substituted pyrrolidinylthio side chain (effect of C-5' substituents).

\begin{tabular}{|c|c|c|c|c|c|c|c|c|c|c|c|}
\hline \multirow{2}{*}{ Organism } & \multicolumn{11}{|c|}{$\mathrm{MIC}(\mu \mathrm{g} / \mathrm{mi})$} \\
\hline & $\mathbf{1 a}$ & $\mathbf{1 b}$ & 1c & 1d & 1e & 1f & $1 \mathrm{~g}$ & 1h & $\mathbf{1 i}$ & $1 \mathrm{j}$ & $\mathbf{1 k}$ \\
\hline S.a. FDA $209 \mathrm{P}$ & $\leq 0.013$ & $\leq 0.013$ & $\leq 0.013$ & 0.025 & $\leq 0.013$ & $\leq 0.013$ & $\leq 0.013$ & 0.025 & $\leq 0.013$ & $\leq 0.013$ & $\leq 0.013$ \\
\hline S.p. Cook & $\leq 0.013$ & $\leq 0.013$ & $\leq 0.013$ & $\leq 0.013$ & $\leq 0.013$ & $\leq 0.013$ & $\leq 0.013$ & $\leq 0.013$ & $\leq 0.013$ & $\leq 0.013$ & $\leq 0.013$ \\
\hline E.c. NIHJ JC-2 & $\leq 0.013$ & $\leq 0.013$ & 0.025 & 0.025 & $\leq 0.013$ & 0.025 & $\leq 0.013$ & 0.05 & $\leq 0.013$ & $\leq 0.013$ & $\leq 0.013$ \\
\hline K.p. АТCC 10031 & $\leq 0.013$ & $\leq 0.013$ & 0.025 & 0.025 & $\leq 0.013$ & $\leq 0.013$ & $\leq 0.013$ & 0.025 & $\leq 0.013$ & $\leq 0.013$ & $\leq 0.013$ \\
\hline P.m. GN 2425 & 0.10 & 0.05 & N.D. & 0.05 & 0.05 & 0.10 & 0.05 & 0.10 & $\leq 0.013$ & 0.05 & 0.05 \\
\hline P.a. IFO 3451 & 0.78 & 1.56 & 25 & 1.56 & 0.78 & 12.5 & 0.78 & 1.56 & 12.5 & 3.13 & 6.25 \\
\hline S.m. X 100 & 0.05 & 0.05 & 0.05 & 0.025 & 0.025 & 0.05 & 0.025 & 0.10 & $\leq 0.013$ & 0.05 & 0.05 \\
\hline E.c. ML 1410/RP4 ${ }^{a}$ & 0.05 & 0.05 & 0.05 & 0.025 & 0.025 & 0.025 & 0.025 & 0.10 & 0.05 & 0.05 & 0.05 \\
\hline E.c. GN $5482^{\mathrm{a}}$ & $\leq 0.013$ & $\leq 0.013$ & 0.025 & 0.025 & $\leq 0.013$ & 0.025 & $\leq 0.013$ & 0.025 & N.D. & $\leq 0.013$ & 0.025 \\
\hline P.v. GN $7919^{\mathrm{a}}$ & 0.10 & 0.10 & 0.20 & 0.10 & 0.05 & 0.20 & 0.05 & 0.10 & 0.05 & 0.05 & 0.10 \\
\hline S.m. GN $6473^{a}$ & 0.10 & 0.10 & 0.20 & 0.10 & 0.20 & 0.10 & 0.05 & 0.10 & 0.05 & 0.05 & 0.10 \\
\hline $\begin{array}{l}\text { DHP-I }{ }^{\mathrm{b}} \\
\mathrm{T}_{1 / 2} \text { (minutes) }\end{array}$ & 16 & 22 & 18 & 16 & 16 & 11 & 7.8 & 11 & 10 & 9.6 & 11 \\
\hline
\end{tabular}

${ }^{a, b}$ and abbreviations: See a footnote in Table 1.

dimethylaminocarbonyl and $5^{\prime}$-pyrrolidinylcarbonyl derivatives were investigated. As shown in Table 3, the introduction of $\beta$-methyl group effectively enhanced not only the stability to DHP-I as previously reported ${ }^{9,11}$, but also the activities against Gram-negative bacteria. Especially, it was interesting that good improvements of the stability to DHP-I and anti-pseudomonal activity were observed by the introduction of $\beta$-methyl group in the case of 5 -dimethylaminocarbonyl derivative (5a). On the other hand, the significant improvement of stability to DHP-I was not observed in the $1 \alpha$-methyl isomer (6a) and moreover its antibacterial activities were decreased ${ }^{11)}$.

Among the carbapenem compounds synthesized, 5a (SM-7338) was the most interesting compound and was selected for further evaluation.

\section{Experimental}

General Analytical Methods

MP's were determined on a Thomas-Hoover capilary melting point apparatus and were uncorrected. IR spectra were recorded on a Hitachi $260-10$ IR spectrophotometer. ${ }^{1} \mathrm{H}$ NMR spectra were taken with Jeol FX-90Q (90 MHz) and JNM-GX270 (270 MHz) FT spectrometers, in the designated solvent, using tetramethylsilane or residual DOH $(\delta 4.80)$ as an internal reference. UV spectra were recorded on a Hitachi 330 UV-VIS spectrophotometer. Mass spectra were obtained on Hitachi DF/GC/MS M-80 and DPS M-003 (3kV) spectrometers. Optical rotations were determined on a Jasco DIP-181 digital polarimeter. Column chromatography was carried out on Silica gel 60 (70 230 mesh, E. Merck).

(2S,4R)-2-Carboxy-4-hydroxy-1-p-nitrobenzyloxycarbonylpyrrolidine (8)

To a solution of trans-4-hydroxy-L-proline $(7)(27.5 \mathrm{~g}, 0.21 \mathrm{~mol})$ and $2 \mathrm{~N} \mathrm{NaOH}(230 \mathrm{ml})$ was added 
dropwise a solution of PNB chloroformate $(49.5 \mathrm{~g}, 0.23 \mathrm{~mol})$ in $\mathrm{CH}_{2} \mathrm{Cl}_{2}(40 \mathrm{ml})$ at $0 \sim 5^{\circ} \mathrm{C}$ and stirred for 2 hours at the same temperature. After addition of $2 \mathrm{~N} \mathrm{NaOH}(50 \mathrm{ml})$, the aqueous layer was separated from the reaction mixture, washed with $\mathrm{CH}_{2} \mathrm{Cl}_{2}(70 \mathrm{ml})$ and acidified with conc $\mathrm{H}_{2} \mathrm{SO}_{4}(38 \mathrm{~g})$ at $0 \sim 5^{\circ} \mathrm{C}$. The resulting crystals were collected by filtration, washed with water and dried under reduced pressure to afford $8\left(60.7 \mathrm{~g}, 93 \%\right.$ ): MP $134 \sim 135.5^{\circ} \mathrm{C}$; IR (Nujol) $\mathrm{cm}^{-1} 3300,1738,1660,1605,1520 ;{ }^{1} \mathrm{H}$ NMR $\left(\mathrm{CD}_{3} \mathrm{OD}\right) \delta 2.13(1 \mathrm{H}, \mathrm{m}), 2.32(1 \mathrm{H}, \mathrm{m}), 3.53 \sim 3.69(2 \mathrm{H}, \mathrm{m}), 4.39 \sim 4.51(2 \mathrm{H}, \mathrm{m}), 5.16(1 \mathrm{H} \times 1 / 2, \mathrm{~d}$, $J=14.0 \mathrm{~Hz}), 5.27(1 \mathrm{H}, \mathrm{s}), 5.33(1 \mathrm{H} \times 1 / 2, \mathrm{~d}, J=14.0 \mathrm{~Hz}), 7.58(1 \mathrm{H}, \mathrm{d}, J=9.0 \mathrm{~Hz}), 7.61(1 \mathrm{H}, \mathrm{d}, J=9.0 \mathrm{~Hz})$, $8.21(2 \mathrm{H}, \mathrm{d}, J=9.0 \mathrm{~Hz}), 8.23(2 \mathrm{H}, \mathrm{d}, J=9.0 \mathrm{~Hz})$.

Anal Calcd for $\mathrm{C}_{13} \mathrm{H}_{14} \mathrm{~N}_{2} \mathrm{O}_{7} \cdot \frac{1}{2} \mathrm{H}_{2} \mathrm{O}: \quad \mathrm{C} 48.90, \mathrm{H} 4.73, \mathrm{~N} 8.77$.

Found:

C $49.68, \mathrm{H} 4.65, \mathrm{~N} 8.72$.

(2S,4R)-4-Hydroxy-2-p-methoxybenzyloxycarbonyl-1-p-nitrobenzyloxycarbonylpyrrolidine (9)

To a solution of $8(15.0 \mathrm{~g} 48 \mathrm{mmol})$ and triethylamine $(13.5 \mathrm{ml}, 97 \mathrm{mmol})$ in DMF $(150 \mathrm{ml})$, PMB chloride $(13.6 \mathrm{~g}, 87 \mathrm{mmol})$ was added dropwise at room temperature under nitrogen atmosphere and stirred for 10 hours at $70^{\circ} \mathrm{C}$. The reaction mixture was diluted with EtOAc $(500 \mathrm{ml})$, washed with water and dried over $\mathrm{Na}_{2} \mathrm{SO}_{4}$. Evaporation of solvents in vacuo gave a crude crystal which was recrystallized from $\mathrm{Et}_{2} \mathrm{O}$ to afford 9 (18.2 g, 88\%): MP $83 \sim 85^{\circ} \mathrm{C}$; IR (Nujol) $\mathrm{cm}^{-1} 3430,1735,1705,1510 ;{ }^{1} \mathrm{H} \mathrm{NMR}\left(\mathrm{CDCl}_{3}\right) \delta$ $2.12(1 \mathrm{H}, \mathrm{m}), 2.34(1 \mathrm{H}, \mathrm{m}), 3.77(3 \mathrm{H} \times 3 / 5, \mathrm{~s}), 3.81(3 \mathrm{H} \times 2 / 5, \mathrm{~s}), 4.55(2 \mathrm{H}, \mathrm{m}), 5.02(1 \mathrm{H} \times 3 / 5, \mathrm{~d}, J=12.0 \mathrm{~Hz})$, $5.06(1 \mathrm{H} \times 3 / 5, \mathrm{~d}, J=12.0 \mathrm{~Hz}), 5.09(2 \mathrm{H}, \mathrm{s}), 5.23(1 \mathrm{H} \times 2 / 5, \mathrm{~d}, J=13.5 \mathrm{~Hz}), 5.26(1 \mathrm{H} \times 2 / 5, \mathrm{~d}, J=13.5 \mathrm{~Hz})$, $6.80(2 \mathrm{H} \times 3 / 5, \mathrm{~d}, J=9.0 \mathrm{~Hz}), 6.87(2 \mathrm{H} \times 2 / 5, \mathrm{~d}, J=9.0 \mathrm{~Hz}), 7.19(2 \mathrm{H} \times 3 / 5, \mathrm{~d}, J=9.0 \mathrm{~Hz}), 7.33(2 \mathrm{H} \times 3 / 5$, d, $J=9.0 \mathrm{~Hz}), 7.50(2 \mathrm{H} \times 2 / 5, \mathrm{~d}, J=9.0 \mathrm{~Hz}), 8.11(2 \mathrm{H} \times 3 / 5, \mathrm{~d}, J=9.0 \mathrm{~Hz}), 8.20(2 \mathrm{H} \times 2 / 5, \mathrm{~d}, J=9.0 \mathrm{~Hz})$.

Anal Calcd for $\mathrm{C}_{21} \mathrm{H}_{22} \mathrm{~N}_{2} \mathrm{O}_{8}$ : C $58.58, \mathrm{H} 5.15, \mathrm{~N} 6.51$. Found:

C 58.43, H 5.13, N 6.40 .

$(2 S, 4 S)$-4-Acetylthio-2-p-methoxybenzyloxycarbonyl-1-p-nitrobenzyloxycarbonylpyrrolidine (10)

To a solution of $9(8.6 \mathrm{~g}, 20 \mathrm{mmol})$ and triphenylphosphine $(7.86 \mathrm{~g}, 30 \mathrm{mmol})$ in THF $(20 \mathrm{ml})$ was added dropwise a solution of diethyl azodicarboxylate $(5.22 \mathrm{~g}, 30 \mathrm{mmol})$ in THF $(5 \mathrm{ml})$ at $0 \sim 5^{\circ} \mathrm{C}$ under nitrogen atmosphere and stirred for 30 minutes at the same temperature. Thioacetic acid $(2.28 \mathrm{~g}, 30 \mathrm{mmol})$ was added dropwise to the mixture. After stirring for 1 hour at $0 \sim 5^{\circ} \mathrm{C}$ and then at room temperature for 3 hours, the reaction mixture was concentrated in vacuo to give an oily residue which was purified by silica gel column chromatography to afford $10(9.7 \mathrm{~g}, 99 \%)$ : IR (neat) $\mathrm{cm}^{-1} 1740$ (sh), 1715, 1520; ${ }^{1} \mathrm{H}$ NMR $\left(\mathrm{CDCl}_{3}\right) \delta 2.31(3 \mathrm{H}, \mathrm{s}), 3.79(3 \mathrm{H}, \mathrm{s}), 5.10(2 \mathrm{H}, \mathrm{s}), 5.24(2 \mathrm{H}, \mathrm{s}), 7.49(2 \mathrm{H}, \mathrm{d}, J=9.0 \mathrm{~Hz}), 8.18(2 \mathrm{H}$, d, $J=9.0 \mathrm{~Hz}) ; \mathrm{MS} m / z 488\left(\mathrm{M}, \mathrm{C}_{23} \mathrm{H}_{24} \mathrm{~N}_{2} \mathrm{O}_{8} \mathrm{~S}\right)$.

(2S,4S)-4-Acetylthio-2-carboxy-1-p-nitrobenzyloxycarbonylpyrrolidine (11)

A mixture of $10(9.76 \mathrm{~g}, 20 \mathrm{mmol})$, anisole $(4.32 \mathrm{~g}, 40 \mathrm{mmol})$ and TFA $(35 \mathrm{ml}, 450 \mathrm{mmol})$ was stirred for 30 minutes at room temperature. The reaction mixture was concentrated in vacuo to give an oily residue which was purified by silica gel column chromatography to afford 11 ( $7.36 \mathrm{~g}$, quantitative yield): MP $107 \sim 109^{\circ} \mathrm{C}$; IR (Nujol) $\mathrm{cm}^{-1} 1725,1685,1660(\mathrm{sh}) ;{ }^{1} \mathrm{H}$ NMR $\left(\mathrm{CDCl}_{3}\right) \delta 2.16(1 \mathrm{H}, \mathrm{m}), 2.35(3 \mathrm{H}, \mathrm{s}), 2.75$ $(1 \mathrm{H}, \mathrm{m}), 3.42(1 \mathrm{H}, \mathrm{dd}, J=6.5$ and $11.0 \mathrm{~Hz}), 4.48(1 \mathrm{H}, \mathrm{t}, J=7.5 \mathrm{~Hz}), 5.10(1 \mathrm{H} \times 1 / 3, \mathrm{~d}, J=13.5 \mathrm{~Hz}), 5.27$ $(2 \mathrm{H} \times 2 / 3, \mathrm{~s}), 5.36(1 \mathrm{H} \times 1 / 3, \mathrm{~d}, J=13.5 \mathrm{~Hz}), 7.45(2 \mathrm{H} \times 1 / 3, \mathrm{~d}, J=8.5 \mathrm{~Hz}), 7.53(2 \mathrm{H} \times 2 / 3, \mathrm{~d}, J=8.5 \mathrm{~Hz})$, $8.20(2 \mathrm{H} \times 1 / 3, \mathrm{~d}, J=8.5 \mathrm{~Hz}), 8.23(2 \mathrm{H} \times 2 / 3, \mathrm{~d}, J=8.5 \mathrm{~Hz})$; FD-MS $m / z 369(\mathrm{M}+\mathrm{H})$.

(2S,4S)-4-Acetylthio-2-dimethylaminocarbonyl-1-p-nitrobenzyloxycarbonylpyrrolidine (12a)

To a solution of $11(6.4 \mathrm{~g}, 17.4 \mathrm{mmol})$ and triethylamine $(3.26 \mathrm{~g}, 32.3 \mathrm{mmol})$ in THF $(80 \mathrm{ml})$ was added dropwise isopropyl chloroformate $(3.45 \mathrm{~g}, 28.1 \mathrm{mmol})$ at $-10 \sim 5^{\circ} \mathrm{C}$ under nitrogen atmosphere and stirred for 20 minutes. Then a $1 \mathrm{M}$ solution of dimethylamine in THF $(39 \mathrm{ml})$ was added to the reaction mixture at $-10 \sim 0^{\circ} \mathrm{C}$. After stirring for 20 minutes, the reaction mixture was poured into cold water and extracted with EtOAc. The extract was successively washed with diluted $\mathrm{HCl}$ and water, and dried over $\mathrm{Na}_{2} \mathrm{SO}_{4}$. Evaporation of the solvents in vacuo gave an oily residue which was purified by silica gel column chromatography to afford 12a $(6.60 \mathrm{~g}, 96 \%)$ : MP $115.5 \sim 119^{\circ} \mathrm{C} ;[\alpha]_{\mathrm{D}}^{30}+5.21^{\circ}\left(c 0.379,\left(\mathrm{CH}_{3}\right)_{2} \mathrm{CO}\right)$; IR (neat) $\mathrm{cm}^{-1} 1705,1650,1515 ;{ }^{1} \mathrm{H}$ NMR $\left(\mathrm{CDCl}_{3}\right) \delta 2.32(3 \mathrm{H}, \mathrm{s}), 2.97(3 \mathrm{H}, \mathrm{s}), 3.11(3 \mathrm{H}, \mathrm{s}), 5.21(2 \mathrm{H}, \mathrm{s}), 8.18$ $(2 \mathrm{H}, \mathrm{d}, J=8.5 \mathrm{~Hz})$. 
Anal Calcd for $\mathrm{C}_{17} \mathrm{H}_{21} \mathrm{~N}_{3} \mathrm{O}_{6} \mathrm{~S}: \quad$ C $51.64, \mathrm{H} 5.35, \mathrm{~N} 10.63, \mathrm{~S} 8.11$

Found:

C 51.45, H 5.32, N 10.51, S 8.40.

The following compounds $(\mathbf{1 2 a} \sim 12 \mathrm{k})$ were prepared from 11 and the corresponding amines as described for the preparation of $\mathbf{1 2 a}$, respectively.

12b: MP $195 \sim 200^{\circ} \mathrm{C}$; IR (Nujol) $\mathrm{cm}^{-1} 3400$ (br), 1695, 1522, 1350; ${ }^{1} \mathrm{H}$ NMR $\left(\mathrm{CDCl}_{3}\right) \delta 2.34(3 \mathrm{H}$, s), $3.40(1 \mathrm{H}, \mathrm{m}), 4.11(1 \mathrm{H}, \mathrm{m}), 5.26(2 \mathrm{H}, \mathrm{s}), 7.52(2 \mathrm{H}, \mathrm{d}, J=8.5 \mathrm{~Hz}), 8.24(2 \mathrm{H}, \mathrm{d}, J=8.5 \mathrm{~Hz})$.

12c: IR (neat) $\mathrm{cm}^{-1} 1710,1650,1520 ;{ }^{1} \mathrm{H}$ NMR $\left(\mathrm{CDCl}_{3}\right) \delta 2.33(3 \mathrm{H}, \mathrm{s}), 4.68(1 \mathrm{H}, \mathrm{t}, J=8.0 \mathrm{~Hz})$, $5.19(2 \mathrm{H}, \mathrm{s}), 8.18(2 \mathrm{H}, \mathrm{d}, J=8.5 \mathrm{~Hz})$.

12d: IR (neat) $\mathrm{cm}^{-1} 1705,1655,1520 ;{ }^{1} \mathrm{H}$ NMR $\left(\mathrm{CDCl}_{3}\right) \delta 2.33(3 \mathrm{H}, \mathrm{s}), 5.20(2 \mathrm{H}, \mathrm{s}), 7.47(2 \mathrm{H}, \mathrm{d}$, $J=8.5 \mathrm{~Hz}), 8.17(2 \mathrm{H}, \mathrm{d}, J=8.5 \mathrm{~Hz})$.

12e: IR (neat) $\mathrm{cm}^{-1} 1705,1640,1516 ;{ }^{1} \mathrm{H} \mathrm{NMR}\left(\mathrm{CDCl}_{3}\right) \delta 2.31(3 \mathrm{H}, \mathrm{s}), 4.03(2 \mathrm{H}, \mathrm{dd}, J=6.0$ and $8.0 \mathrm{~Hz}), 4.53(1 \mathrm{H}, \mathrm{t}, J=8.0 \mathrm{~Hz}), 5.19(2 \mathrm{H}, \mathrm{s}), 7.48(2 \mathrm{H}, \mathrm{d}, J=9.0 \mathrm{~Hz}), 8.18(2 \mathrm{H}, \mathrm{d}, J=9.0 \mathrm{~Hz})$.

12f: IR (neat) $\mathrm{cm}^{-1} 1710,1650,1525 ;{ }^{1} \mathrm{H} \mathrm{NMR}\left(\mathrm{CDCl}_{3}\right) \delta 1.58(6 \mathrm{H}, \mathrm{m}), 2.32(3 \mathrm{H}, \mathrm{s}), 5.22(2 \mathrm{H}, \mathrm{s})$.

12g: IR $\left(\mathrm{CHCl}_{3}\right) \mathrm{cm}^{-1} 1705,1660,1525 ;{ }^{1} \mathrm{H}$ NMR $\left(\mathrm{CDCl}_{3}\right) \delta 2.35(3 \mathrm{H}, \mathrm{s}), 5.23(2 \mathrm{H}, \mathrm{s}), 7.55(2 \mathrm{H}$, $\mathrm{d}, J=9.0 \mathrm{~Hz}$ ).

12h: IR (neat) $\mathrm{cm}^{-1} 3400(\mathrm{sh}), 1685,1640(\mathrm{sh}), 1517 ;{ }^{1} \mathrm{H} \mathrm{NMR}\left(\mathrm{CDCl}_{3}\right) \delta 2.33(3 \mathrm{H}, \mathrm{s}), 2.97(3 \mathrm{H}$, s), $5.20(2 \mathrm{H}, \mathrm{s}), 7.49(2 \mathrm{H}, \mathrm{d}, J=9.0 \mathrm{~Hz}), 8.19(2 \mathrm{H}, \mathrm{d}, J=9.0 \mathrm{~Hz})$.

12i: IR (neat) $\mathrm{cm}^{-1} 1695,1595,1520 ;{ }^{1} \mathrm{H} \mathrm{NMR}\left(\mathrm{CDCl}_{3}\right) \delta 2.34(3 \mathrm{H}, \mathrm{s}), 5.31(2 \mathrm{H}, \mathrm{s}), 7.42(2 \mathrm{H}, \mathrm{d}$, $J=9.0 \mathrm{~Hz}), 8.48(2 \mathrm{H}, \mathrm{d}, J=9.0 \mathrm{~Hz})$.

12j: IR $\left(\mathrm{CHCl}_{3}\right) \mathrm{cm}^{-1} 3350,1690,1660,1520 ;{ }^{1} \mathrm{H} \mathrm{NMR}\left(\mathrm{CDCl}_{3}\right) \delta 2.36(3 \mathrm{H}, \mathrm{s}), 3.21(2 \mathrm{H}, \mathrm{s}), 5.23$ $(2 \mathrm{H}, \mathrm{s}), 6.93(1 \mathrm{H}$, br s$), 7.50(2 \mathrm{H}, \mathrm{d}, J=9.0 \mathrm{~Hz}), 8.25(2 \mathrm{H}, \mathrm{d}, J=9.0 \mathrm{~Hz})$.

12k: MP $200 \sim 206^{\circ} \mathrm{C}$; IR (Nujol) $\mathrm{cm}^{-1} 3310,1710,1635,1520 ;{ }^{1} \mathrm{H}$ NMR (DMSO-d $) 1.19(1 \mathrm{H}, \mathrm{t}$, $J=7.5 \mathrm{~Hz}), 2.35(3 \mathrm{H}, \mathrm{s}), 2.58(3 \mathrm{H}, \mathrm{d}, J=4.5 \mathrm{~Hz}), 3.66(2 \mathrm{H}, \mathrm{d}, J=5.0 \mathrm{~Hz}), 5.22(2 \mathrm{H}, \mathrm{s}), 8.22(2 \mathrm{H}, \mathrm{d}, J=8.5 \mathrm{~Hz})$.

\section{$(2 S, 4 S)$-2-Dimethylaminocarbonyl-4-mercapto-1-p-nitrobenzyloxycarbonylpyrrolidine (13a)}

To a solution of $12 \mathrm{a}(2.5 \mathrm{~g}, 6.33 \mathrm{mmol})$ in $\mathrm{MeOH}(15 \mathrm{ml})$ was added dropwise $4 \mathrm{~N} \mathrm{NaOH}(1.66 \mathrm{ml})$ at $0 \sim 5^{\circ} \mathrm{C}$ and stirred for 15 minutes at the same temperature. After addition of $4 \mathrm{~N} \mathrm{HCl}(1.74 \mathrm{ml})$, the reaction mixture was diluted with EtOAc $(65 \mathrm{ml})$. The separated organic layer was washed with brine and dried over $\mathrm{Na}_{2} \mathrm{SO}_{4}$. Evaporation of the solvents in vacuo gave an oily residue containing $13 \mathrm{a}$ (net $2.06 \mathrm{~g}$, $92 \%$ ) which was used in the next step without further purification. An analytical sample of 13a was prepared as colorless crystals by recrystallization from EtOAc-hexane (1:1): MP $118.5 \sim 119.5^{\circ} \mathrm{C} ;[\alpha]_{\mathrm{D}}^{20}$ $+9.60^{\circ}\left(c 1.01, \mathrm{CHCl}_{3}\right) ; \mathrm{IR}$ (neat) $\mathrm{cm}^{-1} 1705,1650,1515 ;{ }^{1} \mathrm{H} \mathrm{NMR}\left(\mathrm{CDCl}_{3}\right) \delta 1.90(1 \mathrm{H}, \mathrm{d}, J=8.0 \mathrm{~Hz})$, $2.97(3 \mathrm{H}, \mathrm{s}), 3.08(3 \mathrm{H}, \mathrm{s}), 5.19(2 \mathrm{H}, \mathrm{s}), 7.48(2 \mathrm{H}, \mathrm{d}, J=9.0 \mathrm{~Hz}), 8.15(2 \mathrm{H}, \mathrm{d}, J=9.0 \mathrm{~Hz})$.

Anal Calcd for $\mathrm{C}_{15} \mathrm{H}_{19} \mathrm{~N}_{3} \mathrm{O}_{5} \mathrm{~S} \cdot \frac{1}{4} \mathrm{H}_{2} \mathrm{O}:$ C 50.34, $\mathrm{H} 5.49, \mathrm{~N} 11.74, \mathrm{~S} 8.96$.

Found:

C 50.55 , H 5.40 , N 11.77 , S 9.10

Mercaptans $(13 b \sim 13 k)$ were prepared from $12 b \sim 12 k$ as described for the preparation of 13a, respectively, and also used in the next step without further purification.

$(2 S, 4 S)$-4-Formyloxy-2-p-methoxybenzyloxycarbonyl-1-p-nitrobenzyloxycarbonylpyrrolidine (14)

To a solution of $9(16.57 \mathrm{~g}, 38.5 \mathrm{mmol})$, formic acid $(2.66 \mathrm{~g}, 57.8 \mathrm{mmol})$ and triphenylphosphine $(20.19 \mathrm{ml}, 77.1 \mathrm{mmol})$ in THF $(38 \mathrm{ml})$ was added dropwise a solution of diethyl azodicarboxylate $(13.41 \mathrm{~g}$, $77.1 \mathrm{mmol})$ in THF $(19 \mathrm{ml})$ at room temperature under nitrogen atmosphere. After stirring for 30 minutes, the reaction mixture was concentrated in vacuo to give an oily residue which was purified by silica gel column chromatography to afford $14\left(14.46 \mathrm{~g}, 82 \%\right.$ ): IR (neat) $\mathrm{cm}^{-1} 1740$ (sh), 1710, 1512; ${ }^{1} \mathrm{H}$ NMR $\left(\mathrm{CDCl}_{3}\right) \delta 3.80(3 \mathrm{H}, \mathrm{s}), 4.59(1 \mathrm{H}, \mathrm{m}), 5.10(2 \mathrm{H}, \mathrm{s}), 5.23(1 \mathrm{H}, \mathrm{d}, J=13.0 \mathrm{~Hz}), 5.41(1 \mathrm{H}, \mathrm{m}), 6.84(1 \mathrm{H}, \mathrm{d}$, $J=8.5 \mathrm{~Hz}), 7.39(1 \mathrm{H}, \mathrm{d}, J=9.0 \mathrm{~Hz}), 7.50(1 \mathrm{H}, \mathrm{d}, J=8.5 \mathrm{~Hz}), 8.14(1 \mathrm{H}, \mathrm{d}, J=9.0 \mathrm{~Hz}), 8.21(1 \mathrm{H}, \mathrm{d}, J=8.5 \mathrm{~Hz})$, $9.23(1 \mathrm{H}, \mathrm{s})$.

(2S,4S)-4-Hydroxy-2-p-methoxybenzyloxycarbonyl-1-p-nitrobenzyloxycarbonylpyrrolidine (15)

To a solution of $14(2.37 \mathrm{~g}, 5.17 \mathrm{mmol})$ in THF $(12 \mathrm{ml})$ was added dropwise $1 \mathrm{~N} \mathrm{NaOH}(10 \mathrm{ml})$ at $0 \sim 5^{\circ} \mathrm{C}$ and stirred for 10 minutes at the same temperature. The reaction mixture was diluted with EtOAc, washed with brine and dried over $\mathrm{Na}_{2} \mathrm{SO}_{4}$. Evaporation of solvents in vacuo gave a crude crystal which was recrystallized from $\mathrm{Et}_{2} \mathrm{O}$ to afford $15\left(1.69 \mathrm{~g}, 76 \%\right.$ ): IR (neat) $\mathrm{cm}^{-1} 3400,1725,1515:{ }^{1} \mathrm{H}$ NMR 
$\left(\mathrm{CDCl}_{3}\right) \delta 3.78(3 \mathrm{H}, \mathrm{s}), 5.08(2 \mathrm{H}, \mathrm{s}), 6.82(2 \mathrm{H}, \mathrm{d}, J=9.0 \mathrm{~Hz}), 8.12(2 \mathrm{H}, \mathrm{d}, J=9.0 \mathrm{~Hz})$.

$(2 S, 4 R)$-Isomers (16 and 17) were prepared from 15 by the method described for the preparation of the corresponding $(2 S, 4 S)$-isomers.

16a: $[\alpha]_{\mathrm{D}}^{30}+32.8^{\circ}\left(c 0.375,\left(\mathrm{CH}_{3}\right)_{2} \mathrm{CO}\right)$; IR (neat) $\mathrm{cm}^{-1} 1700,1655,1515 ;{ }^{1} \mathrm{H}$ NMR $\left(\mathrm{CDCl}_{3}\right) \delta 2.33$ $(3 \mathrm{H}, \mathrm{s}), 2.97(3 \mathrm{H}, \mathrm{s}), 3.16(3 \mathrm{H}, \mathrm{s}), 5.22(2 \mathrm{H}, \mathrm{s}), 8.16(2 \mathrm{H}, \mathrm{d}, J=8.5 \mathrm{~Hz})$.

16b: $[\alpha]_{\mathrm{D}}^{30}+7.36^{\circ}\left(c 0.625,\left(\mathrm{CH}_{3}\right)_{2} \mathrm{CO}\right)$; IR (neat) $\mathrm{cm}^{-1} 3300$ (br), 1700 (sh), 1685, 1512; ${ }^{1} \mathrm{H}$ NMR $\left(\mathrm{CDCl}_{3}\right) \delta 2.31(3 \mathrm{H}, \mathrm{s}), 5.22(2 \mathrm{H}, \mathrm{s}), 8.11(2 \mathrm{H}, \mathrm{d}, J=8.5 \mathrm{~Hz})$.

$(2 R, 4 S)$ and $(2 R, 4 R)$-isomers $(21,22,23$ and 24$)$ were prepared from cis-4-hydroxy-D-proline (20) by the method described for the preparation of the corresponding $(2 S, 4 S)$ and $(2 S, 4 R)$-isomers.

21a: $[\alpha]_{\mathrm{D}}^{30}-29.6^{\circ}\left(c 0.215,\left(\mathrm{CH}_{3}\right)_{2} \mathrm{CO}\right)$; IR (neat) $\mathrm{cm}^{-1} 1700,1650,1520 ;{ }^{1} \mathrm{H}$ NMR $\left(\mathrm{CDCl}_{3}\right) \delta 2.33$ $(3 \mathrm{H}, \mathrm{s}), 2.99(3 \mathrm{H}, \mathrm{s}), 3.10(3 \mathrm{H}, \mathrm{s}), 5.22(2 \mathrm{H}, \mathrm{s}), 7.50(1 \mathrm{H}, \mathrm{d}, J=9.0 \mathrm{~Hz}), 8.21(2 \mathrm{H}, \mathrm{d}, J=9.0 \mathrm{~Hz})$.

21b: $[\alpha]_{\mathrm{D}}^{30}-6.92^{\circ}\left(c 0.665,\left(\mathrm{CH}_{3}\right)_{2} \mathrm{CO}\right)$; IR (neat) $\mathrm{cm}^{-1} 1705,1685,1520$.

23a: $[\alpha]_{\mathrm{D}}^{30}-7.38^{\circ}\left(c 0.210,\left(\mathrm{CH}_{3}\right)_{2} \mathrm{CO}\right)$; IR (neat) $\mathrm{cm}^{-1} 1705,1650,1515 ;{ }^{1} \mathrm{H} \mathrm{NMR}\left(\mathrm{CDCl}_{3}\right) \delta 1.90$ $(1 \mathrm{H}, \mathrm{m}), 2.34(3 \mathrm{H}, \mathrm{s}), 2.75(1 \mathrm{H}, \mathrm{m}), 2.99(3 \mathrm{H} \times 5 / 7, \mathrm{~s}), 3.10(3 \mathrm{H} \times 5 / 7, \mathrm{~s}), 3.46(1 \mathrm{H}, \mathrm{t}, J=10.0 \mathrm{~Hz}), 3.99$ $(1 \mathrm{H}, \mathrm{m}), 4.13(1 \mathrm{H}, \mathrm{dd}, J=7.5$ and $11.0 \mathrm{~Hz}), 4.75(1 \mathrm{H}, \mathrm{m}), 5.22(2 \mathrm{H} \times 5 / 7, \mathrm{~s}), 8.22(2 \mathrm{H}, \mathrm{d}, J=8.5 \mathrm{~Hz})$.

23b: $[\alpha]_{\mathrm{D}}^{30}+39.6^{\circ}(c 0.293, \mathrm{DMF})$; IR (neat) $\mathrm{cm}^{-1} 1685,1515$.

\section{(2S,4R)-2-Dimethylaminocarbonyl-4-hydroxy-1-p-nitrobenzyloxycarbonylpyrrolidine (18a)}

To a solution of $8(8.7 \mathrm{~g}, 28 \mathrm{mmol})$ and triethylamine $(4.25 \mathrm{~g}, 42 \mathrm{mmol})$ in $\mathrm{CH}_{2} \mathrm{Cl}_{2}(80 \mathrm{ml})$ was added isopropyl chloroformate $(5.15 \mathrm{~g}, 42 \mathrm{mmol})$ dropwise at $-10 \sim 0^{\circ} \mathrm{C}$ under nitrogen atmosphere and the mixture was stirred for 1 hour at the same temperature. Dimethylamine hydrochloric acid salt $(4.57 \mathrm{~g}$, $56 \mathrm{mmol})$ and then triethylamine $(8.48 \mathrm{~g}, 84 \mathrm{mmol})$ were added to the reaction mixture at $-10 \sim 0^{\circ} \mathrm{C}$. After stirring for 1 hour, the reaction mixture was successively washed with $1 \mathrm{~N} \mathrm{HCl}$, brine, $5 \% \mathrm{NaHCO}_{3}$ and brine, and dried over $\mathrm{MgSO}_{4}$. Evaporation of the solvents in vacuo gave 18a (9.35 g, 99\%): IR (Nujol) $\mathrm{cm}^{-1} 3430,1695,1642 ;{ }^{1} \mathrm{H}$ NMR $\left(\mathrm{CDCl}_{3}\right) \delta 2.13(2 \mathrm{H}, \mathrm{m}), 2.90(3 \mathrm{H} \times 1 / 3, \mathrm{~s}), 2.99(3 \mathrm{H}, \mathrm{s}), 3.14(3 \mathrm{H} \times 2 / 3$, $\mathrm{s}), 3.70(2 \mathrm{H}, \mathrm{m}), 4.53(1 \mathrm{H}, \mathrm{m}), 5.20(2 \mathrm{H}, \mathrm{s}), 8.19(2 \mathrm{H}, \mathrm{d}, J=8.5 \mathrm{~Hz})$.

(2S,4R)-2-Dimethylaminocarbonyl-4-mesyloxy-1-p-nitrobenzyloxycarbonylpyrrolidine (19a)

To a suspension of $18 \mathrm{a}(9.35 \mathrm{~g}, 27.7 \mathrm{mmol})$ and triethylamine $(3.36 \mathrm{~g}, 33.2 \mathrm{mmol})$ in $\mathrm{CH}_{2} \mathrm{Cl}_{2}(50 \mathrm{ml})$, methanesulfonyl chloride $(3.81 \mathrm{~g}, 33.2 \mathrm{mmol})$ was added dropwise at $-10 \sim 0^{\circ} \mathrm{C}$ under nitrogen atmosphere. After stirring for 1 hour at the same temperature, the reaction mixture was successively washed with brine, $5 \% \mathrm{NaHCO}_{3}$ and brine, and dried over $\mathrm{MgSO}_{4}$. Evaporation of the solvents in vacuo gave a crude crystal which was recrystallized from $\mathrm{MeOH}$ - hexane $(2: 1)$ to give $19 \mathrm{a}(8.38 \mathrm{~g}, 73 \%)$ as a colorless crystal: MP $115 \sim 116^{\circ} \mathrm{C}$; IR (Nujol) cm ${ }^{-1} 1702,1638,1510 ;{ }^{1} \mathrm{H}$ NMR $\left(\mathrm{CDCl}_{3}\right) \delta 2.34(1 \mathrm{H}, \mathrm{m}), 2.92(3 \mathrm{H} \times 1 / 3, \mathrm{~s})$, $3.00(3 \mathrm{H}, \mathrm{s}), 3.06(3 \mathrm{H}, \mathrm{s}), 3.16(3 \mathrm{H} \times 2 / 3, \mathrm{~s}), 4.89(1 \mathrm{H}, \mathrm{m}), 5.07(1 \mathrm{H} \times 1 / 3, \mathrm{~d}, J=13.5 \mathrm{~Hz}), 5.24(2 \mathrm{H} \times 2 / 3$, s), $5.37(1 \mathrm{H} \times 1 / 3, \mathrm{~d}, J=13.5 \mathrm{~Hz}), 7.45(2 \mathrm{H} \times 1 / 3, \mathrm{~d}, J=9.0 \mathrm{~Hz}), 7.51(2 \mathrm{H} \times 2 / 3, \mathrm{~d}, J=9.0 \mathrm{~Hz}), 8.23(2 \mathrm{H}$, d, $J=9.0 \mathrm{~Hz}$ ).

$\begin{array}{lll}\text { Anal Calcd for } \mathrm{C}_{16} \mathrm{H}_{21} \mathrm{~N}_{3} \mathrm{O}_{8} \mathrm{~S}: & \mathrm{C} 46.26, \mathrm{H} 5.10, \mathrm{~N} 10.12, \mathrm{~S} 7.72 . \\ & \mathrm{C} 45.96, \mathrm{H} 5.11, \mathrm{~N} 9.98, \mathrm{~S} 7.70 .\end{array}$

(2S,4R)-4-Acetylthio-2-dimethylaminocarbonyl-1-p-nitrobenzyloxycarbonylpyrrolidine (12a)

A mixture of 19a $(9.8 \mathrm{~g}, 23.6 \mathrm{mmol})$ and potassium thioacetate $(4.04 \mathrm{~g}, 35.4 \mathrm{mmol})$ in DMF (30 ml) and toluene $(30 \mathrm{ml})$ was stirred at $65 \sim 70^{\circ} \mathrm{C}$ for 6 hours under nitrogen atmosphere. After cooling, the reaction mixture was diluted with toluene $(190 \mathrm{ml})$ and water $(170 \mathrm{ml})$. Aqueous layer was re-extracted with toluene $(50 \mathrm{ml})$. The combined organic layer was washed with brine and dried over $\mathrm{MgSO}_{4}$. Evaporation of the solvents in vacuo gave an oily residue which was purified by silica gel column chromatography to give 12a $(7.92 \mathrm{~g}, 85 \%)$. This compound was identified by comparison of IR and NMR spectra with the sample prepared from 11.

PNB $(5 R, 6 S)-2-[(3 S, 5 S)$-(5-Dimethylaminocarbonyl-1-p-nitrobenzyloxycarbonyl)pyrrolidin3-ylthio]-6-[(R)-1-p-nitrobenzyloxycarbonyloxyethyl]-carbapen-2-em-3-carboxylate (26a)

To a solution of PNB $(5 R, 6 S)-[(R)-1-p$-nitrobenzyloxycarbonyloxyethyl]-2-oxocarbapenam-3-carboxylate (25) $(2.11 \mathrm{~g}, 4.0 \mathrm{mmol})$ and diisopropylethylamine $(1.55 \mathrm{~g}, 12 \mathrm{mmol})$ in $\mathrm{CH}_{3} \mathrm{CN}(42 \mathrm{ml})$ was added 
diphenyl chlorophosphate $(1.18 \mathrm{~g}, 4.4 \mathrm{mmol})$ at $0 \sim 5^{\circ} \mathrm{C}$ under nitrogen atmosphere. After stirring for 20 minutes, a solution of mercaptan $(13 \mathrm{a}, 1.62 \mathrm{~g}, 4.6 \mathrm{mmol})$ in $\mathrm{CH}_{3} \mathrm{CN}(10 \mathrm{ml})$ was added to this mixture at the same temperature and followed by stirring for 2 hours. The reaction mixture was diluted with EtOAc, washed with brine and dried over $\mathrm{MgSO}_{4}$. Evaporation of the solvents in vacuo gave an oily residue which was purified by silica gel column chromatography $\left(\mathrm{CHCl}_{3}-\left(\mathrm{CH}_{3}\right)_{2} \mathrm{CO}, 19: 1\right)$ to give $26 \mathrm{a}(2.62 \mathrm{~g}, 76 \%)$ as a colorless powder: $[\alpha]_{\mathrm{D}}^{28}+7.7^{\circ}\left(c 0.303,\left(\mathrm{CH}_{3}\right)_{2} \mathrm{CO}\right)$; IR (neat) $\mathrm{cm}^{-1} 1780,1745,1705,1650,1606$, $1515 ;{ }^{1} \mathrm{H}$ NMR $\left(\mathrm{CDCl}_{3}\right) \delta 1.49(3 \mathrm{H}, \mathrm{d}, J=6.0 \mathrm{~Hz}), 2.99(3 \mathrm{H}, \mathrm{s}), 3.11(3 \mathrm{H}, \mathrm{s}), 5.23(1 \mathrm{H}, \mathrm{d}, J=14.0 \mathrm{~Hz})$, $5.25(4 \mathrm{H}, \mathrm{s}), 5.46(1 \mathrm{H}, \mathrm{d}, J=14.0 \mathrm{~Hz}), 7.53(4 \mathrm{H}, \mathrm{d}, J=8.5 \mathrm{~Hz}), 7.62(2 \mathrm{H}, \mathrm{d}, J=8.5 \mathrm{~Hz}), 8.18(6 \mathrm{H}, \mathrm{d}$, $J=8.5 \mathrm{~Hz})$ : FD-MS $m / z 863(\mathrm{M}+\mathrm{H})$.

The following compounds (26b $\sim \mathbf{2 6 k}$ ) were prepared from 25 via enolphosphate as described for the preparation of $26 \mathrm{a}$, respectively.

26b: MP $138 \sim 142^{\circ} \mathrm{C}$; IR (Nujol) $\mathrm{cm}^{-1} 3420,1785,1742,1710,1677,1510 ;{ }^{1} \mathrm{H}$ NMR $\left(\mathrm{CDCl}_{3}\right) \delta 1.47$ $(3 \mathrm{H}, \mathrm{d}, J=6.5 \mathrm{~Hz}), 3.20(2 \mathrm{H}, \mathrm{br} \mathrm{d}, J=8.5 \mathrm{~Hz}), 5.16(2 \mathrm{H}, \mathrm{d}, J=13.0 \mathrm{~Hz}), 5.24(4 \mathrm{H}, \mathrm{s}), 5.44(2 \mathrm{H}, \mathrm{d}, J=13.0 \mathrm{~Hz})$, $7.46(2 \mathrm{H}, \mathrm{d}, J=9.0 \mathrm{~Hz}), 7.52(2 \mathrm{H}, \mathrm{d}, J=9.0 \mathrm{~Hz}), 7.60(2 \mathrm{H}, \mathrm{d}, J=9.0 \mathrm{~Hz}), 8.13(2 \mathrm{H}, \mathrm{d}, J=9.0 \mathrm{~Hz}), 8.15(2 \mathrm{H}$, d, $J=9.0 \mathrm{~Hz}), 8.19(2 \mathrm{H}, \mathrm{d}, J=9.0 \mathrm{~Hz})$.

26c: IR $\left(\mathrm{CHCl}_{3}\right) \mathrm{cm}^{-1} 1780,1746,1708,1656,1610,1525 ;{ }^{1} \mathrm{H}$ NMR $\left(\mathrm{CDCl}_{3}\right) \delta 1.48(3 \mathrm{H}, \mathrm{d}, J=6.0 \mathrm{~Hz})$, $5.27(4 \mathrm{H}, \mathrm{s}), 8.20(6 \mathrm{H}, \mathrm{d}, J=9.0 \mathrm{~Hz})$.

26d: IR (neat) $\mathrm{cm}^{-1} 1782,1750,1710,1660,1522 ;{ }^{1} \mathrm{H}$ NMR $\left(\mathrm{CDCl}_{3}\right) \delta 1.48(3 \mathrm{H}, \mathrm{d}, J=6.0 \mathrm{~Hz}), 5.18$ $(1 \mathrm{H}, \mathrm{d}, J=14.0 \mathrm{~Hz}), 5.26(4 \mathrm{H}, \mathrm{s}), 5.42(1 \mathrm{H}, \mathrm{d}, J=14.0 \mathrm{~Hz}), 7.50(2 \mathrm{H}, \mathrm{d}, J=8.5 \mathrm{~Hz}), 7.53(2 \mathrm{H}, \mathrm{d}, J=8.5 \mathrm{~Hz})$, $7.62(2 \mathrm{H}, \mathrm{d}, J=8.5 \mathrm{~Hz}), 8.19(6 \mathrm{H}, \mathrm{d}, J=8.5 \mathrm{~Hz})$.

26e: IR (neat) $\mathrm{cm}^{-1} 1780,1745,1705,1645,1520 ;{ }^{1} \mathrm{H} \mathrm{NMR}\left(\mathrm{CDCl}_{3}\right) \delta 1.49(3 \mathrm{H}, \mathrm{d}, J=6.5 \mathrm{~Hz}), 5.24$ $(1 \mathrm{H}, \mathrm{d}, J=14.0 \mathrm{~Hz}), 5.26(4 \mathrm{H}, \mathrm{s}), 5.43(1 \mathrm{H}, \mathrm{d}, J=14.0 \mathrm{~Hz}), 7.44(2 \mathrm{H}, \mathrm{d}, J=9.0 \mathrm{~Hz}), 7.48(2 \mathrm{H}, \mathrm{d}, J=9.0 \mathrm{~Hz})$, $7.68(2 \mathrm{H}, \mathrm{d}, J=9.0 \mathrm{~Hz}), 8.19(6 \mathrm{H}, \mathrm{d}, J=9.0 \mathrm{~Hz})$.

26f: IR (neat) $\mathrm{cm}^{-1} 1775,1750,1705,1640,1520 ;{ }^{1} \mathrm{H} \mathrm{NMR}\left(\mathrm{CDCl}_{3}\right) \delta 1.48(3 \mathrm{H}, \mathrm{d}, J=6.5 \mathrm{~Hz}), 5.23$ $(1 \mathrm{H}, \mathrm{d}, J=14.0 \mathrm{~Hz}), 5.24(4 \mathrm{H}, \mathrm{s}), 5.44(1 \mathrm{H}, \mathrm{d}, J=14.0 \mathrm{~Hz}), 8.19(6 \mathrm{H}, \mathrm{d}, J=8.5 \mathrm{~Hz})$.

26g: IR $\left(\mathrm{CHCl}_{3}\right) \mathrm{cm}^{-1} 1780,1745,1708,1660,1623,1606,1520 ;{ }^{1} \mathrm{H}$ NMR $\left(\mathrm{CDCl}_{3}\right) \delta 1.49(3 \mathrm{H}, \mathrm{d}$, $J=6.0 \mathrm{~Hz}), 5.26(4 \mathrm{H}, \mathrm{s}), 8.18(6 \mathrm{H}, \mathrm{d}, J=9.0 \mathrm{~Hz})$.

26h: IR (neat) $\mathrm{cm}^{-1} 3400,1778,1745,1700,1650,1520 ;{ }^{1} \mathrm{H} \mathrm{NMR}\left(\mathrm{CDCl}_{3}\right) \delta 1.48(3 \mathrm{H}, \mathrm{d}, J=6.5 \mathrm{~Hz})$, $3.00(3 \mathrm{H}, \mathrm{s}), 5.20(2 \mathrm{H}, \mathrm{s}), 5.25(2 \mathrm{H}, \mathrm{s}), 5.25(1 \mathrm{H}, \mathrm{d}, J=13.5 \mathrm{~Hz}), 5.45(1 \mathrm{H}, \mathrm{d}, J=13.5 \mathrm{~Hz}), 7.49(2 \mathrm{H}, \mathrm{d}$, $J=8.5 \mathrm{~Hz}), 7.51(2 \mathrm{H}, \mathrm{d}, J=8.5 \mathrm{~Hz}), 7.63(2 \mathrm{H}, \mathrm{d}, J=8.5 \mathrm{~Hz}), 8.19(4 \mathrm{H}, \mathrm{d}, J=8.5 \mathrm{~Hz}), 8.21(2 \mathrm{H}, \mathrm{d}, J=8.5 \mathrm{~Hz})$.

26i: MP $189 \sim 191^{\circ} \mathrm{C}$ (dec); IR (Nujol) $\mathrm{cm}^{-1} 1790,1745,1705,1670,1605,1515 ;{ }^{1} \mathrm{H}$ NMR $\left(\mathrm{CDCl}_{3}\right)$ $\delta 1.49(3 \mathrm{H}, \mathrm{d}, J=6.5 \mathrm{~Hz}), 5.26(4 \mathrm{H}, \mathrm{s}), 5.35(1 \mathrm{H}, \mathrm{d}, J=14.5 \mathrm{~Hz}), 7.46(2 \mathrm{H}, \mathrm{d}, J=8.5 \mathrm{~Hz}), 7.54(2 \mathrm{H}, \mathrm{d}$, $J=8.5 \mathrm{~Hz}), 7.60(2 \mathrm{H}, \mathrm{d}, J=8.5 \mathrm{~Hz}), 8.20(2 \mathrm{H}, \mathrm{d}, J=8.5 \mathrm{~Hz}), 8.23(2 \mathrm{H}, \mathrm{d}, J=8.5 \mathrm{~Hz}), 8.48(2 \mathrm{H}, \mathrm{d}, J=5.0 \mathrm{~Hz})$.

26j: IR $\left(\mathrm{CHCl}_{3}\right) \mathrm{cm}^{-1} 1778,1743,1685,1660,1605,1520 ;{ }^{1} \mathrm{H}$ NMR $\left(\mathrm{CDCl}_{3}\right) \delta 1.48(3 \mathrm{H}, \mathrm{d}, J=6.0 \mathrm{~Hz})$, $2.72(3 \mathrm{H}, \mathrm{d}, J=5.0 \mathrm{~Hz}), 3.19(3 \mathrm{H}, \mathrm{s}), 5.22(2 \mathrm{H}, \mathrm{s}), 5.25(2 \mathrm{H}, \mathrm{s}), 8.22(6 \mathrm{H}, \mathrm{d}, J=9.0 \mathrm{~Hz})$.

26k: MP $167 \sim 169^{\circ} \mathrm{C}$ (dec); IR (Nujol) $\mathrm{cm}^{-1} 1795,1747,1712,1640,1608,1517 ;{ }^{1} \mathrm{H}$ NMR (DMSO- $d_{6}$ ) $\delta 1.34(3 \mathrm{H}, \mathrm{d}, J=6.5 \mathrm{~Hz}), 3.30(3 \mathrm{H}, \mathrm{s}), 3.67(2 \mathrm{H}, \mathrm{d}, J=5.0 \mathrm{~Hz}), 5.30(4 \mathrm{H}, \mathrm{s}), 7.64(4 \mathrm{H}, \mathrm{d}, J=8.5 \mathrm{~Hz}), 7.69$ $(2 \mathrm{H}, \mathrm{d}, J=8.5 \mathrm{~Hz}), 8.22(6 \mathrm{H}, \mathrm{d}, J=8.5 \mathrm{~Hz})$.

The following stereoisomers of $\mathrm{C}-2$ side chain $(29 \mathrm{a}, 29 \mathrm{~b}, 30 \mathrm{a}, 30 \mathrm{~b}, 31 \mathrm{a}$ and $31 \mathrm{~b})$ were prepared from 25 via enolphosphate as described for the preparation of $\mathbf{2 6 a}$, respectively.

29a: $[\alpha]_{\mathrm{D}}^{27}+31.1^{\circ}\left(c 0.193,\left(\mathrm{CH}_{3}\right)_{2} \mathrm{CO}\right)$; IR (neat) $\mathrm{cm}^{-1} 1775,1745,1705,1650,1520 ;{ }^{1} \mathrm{H}$ NMR $\left(\mathrm{CDCl}_{3}\right) \delta 1.48(3 \mathrm{H}, \mathrm{d}, J=6.0 \mathrm{~Hz}), 2.96(3 \mathrm{H}, \mathrm{s}), 3.12(3 \mathrm{H}, \mathrm{s}), 5.22(4 \mathrm{H}, \mathrm{s}), 7.44(2 \mathrm{H}, \mathrm{d}, J=8.5 \mathrm{~Hz}), 7.50$ $(2 \mathrm{H}, \mathrm{d}, J=8.5 \mathrm{~Hz}), 7.58(2 \mathrm{H}, \mathrm{d}, J=8.5 \mathrm{~Hz}), 8.17(6 \mathrm{H}, \mathrm{d}, J=8.5 \mathrm{~Hz})$.

$29 \mathrm{~b}:[\alpha]_{\mathrm{D}}^{29}+37.3^{\circ}\left(c 0.244,\left(\mathrm{CH}_{3}\right)_{2} \mathrm{CO}\right)$; IR (neat) $\mathrm{cm}^{-1} 1775,1745,1700,1520 ;{ }^{1} \mathrm{H} \mathrm{NMR}\left(\mathrm{CDCl}_{3}\right)$ $\delta 1.48(3 \mathrm{H}, \mathrm{d}, J=6.5 \mathrm{~Hz}), 3.22(2 \mathrm{H}, \mathrm{br} \mathrm{d}, J=9.0 \mathrm{~Hz}), 5.25(1 \mathrm{H}, \mathrm{d}, J=14.0 \mathrm{~Hz}), 5.26(4 \mathrm{H}, \mathrm{s}), 5.46(1 \mathrm{H}, \mathrm{d}$, $J=14.0 \mathrm{~Hz}), 7.50(2 \mathrm{H}, \mathrm{d}, J=9.0 \mathrm{~Hz}), 7.54(2 \mathrm{H}, \mathrm{d}, J=9.0 \mathrm{~Hz}), 7.60(2 \mathrm{H}, \mathrm{d}, J=9.0 \mathrm{~Hz}), 8.18(4 \mathrm{H}, \mathrm{d}$, $J=9.0 \mathrm{~Hz}), 8.21(2 \mathrm{H}, \mathrm{d}, J=9.0 \mathrm{~Hz})$.

30a: $[\alpha]_{\mathrm{D}}^{29}+26.8^{\circ}\left(c 0.243,\left(\mathrm{CH}_{3}\right)_{2} \mathrm{CO}\right)$; IR (neat) $\mathrm{cm}^{-1} 1775,1745,1705,1650,1520 ;{ }^{1} \mathrm{H}$ NMR $\left(\mathrm{CDCl}_{3}\right) \delta 1.49(3 \mathrm{H}, \mathrm{d}, J=6.5 \mathrm{~Hz}), 2.98(3 \mathrm{H}, \mathrm{s}), 3.16(3 \mathrm{H}, \mathrm{s}), 5.19(1 \mathrm{H}, \mathrm{d}, J=14.0 \mathrm{~Hz}), 5.27(4 \mathrm{H}, \mathrm{s}), 5.47$ $(1 \mathrm{H}, \mathrm{d}, J=14.0 \mathrm{~Hz}), 7.50(2 \mathrm{H}, \mathrm{d}, J=8.5 \mathrm{~Hz}), 7.55(2 \mathrm{H}, \mathrm{d}, J=8.5 \mathrm{~Hz}), 7.64(2 \mathrm{H}, \mathrm{d}, J=8.5 \mathrm{~Hz}), 8.20(4 \mathrm{H}$, $\mathrm{d}, J=8.5 \mathrm{~Hz}), 8.22(2 \mathrm{H}, \mathrm{d}, J=8.5 \mathrm{~Hz})$.

30b: $[\alpha]_{\mathrm{D}}^{25}+43.7^{\circ}\left(c 0.353,\left(\mathrm{CH}_{3}\right)_{2} \mathrm{CO}\right)$; IR (neat) $\mathrm{cm}^{-1} 1775,1750,1700,1520 ;{ }^{1} \mathrm{H}$ NMR $\left(\mathrm{CDCl}_{3}\right)$ $\delta 1.48(3 \mathrm{H}, \mathrm{d}, J=6.5 \mathrm{~Hz}), 3.26(2 \mathrm{H}, \mathrm{br} \mathrm{d}, J=9.0 \mathrm{~Hz}), 5.18(1 \mathrm{H}, \mathrm{d}, J=14.0 \mathrm{~Hz}), 5.25(4 \mathrm{H}, \mathrm{s}), 5.46(1 \mathrm{H}, \mathrm{d}$, 
$J=14.0 \mathrm{~Hz}), 7.49(2 \mathrm{H}, \mathrm{d}, J=8.5 \mathrm{~Hz}), 7.53(2 \mathrm{H}, \mathrm{d}, J=8.5 \mathrm{~Hz}), 7.62(2 \mathrm{H}, \mathrm{d}, J=8.5 \mathrm{~Hz}), 8.17(4 \mathrm{H}, \mathrm{d}$, $J=8.5 \mathrm{~Hz}), 8.19(2 \mathrm{H}, \mathrm{d}, J=8.5 \mathrm{~Hz})$.

31a: $[\alpha]_{\mathrm{D}}^{30}+23.3^{\circ}\left(c 0.329,\left(\mathrm{CH}_{3}\right)_{2} \mathrm{CO}\right)$; IR (neat) $\mathrm{cm}^{-1} 1775,1745,1705,1650,1520 ;{ }^{1} \mathrm{H}$ NMR $\left(\mathrm{CDCl}_{3}\right) \delta 1.49(3 \mathrm{H}, \mathrm{d}, J=6.5 \mathrm{~Hz}), 2.98(3 \mathrm{H}, \mathrm{s}), 3.09(3 \mathrm{H}, \mathrm{s}), 5.25(4 \mathrm{H}, \mathrm{s}), 5.26(1 \mathrm{H}, \mathrm{d}, J=14.0 \mathrm{~Hz}), 5.44$ $(1 \mathrm{H}, \mathrm{d}, J=14.0 \mathrm{~Hz}), 8.20(6 \mathrm{H}, \mathrm{d}, J=8.5 \mathrm{~Hz})$.

$31 \mathrm{~b}:[\alpha]_{\mathrm{D}}^{32}+57.6^{\circ}\left(c 0.279,\left(\mathrm{CH}_{3}\right)_{2} \mathrm{CO}\right)$; IR (neat) $\mathrm{cm}^{-1} 1780,1745,1700,1610,1520 ;{ }^{1} \mathrm{H}$ NMR $\left(\mathrm{CDCl}_{3}\right) \delta 1.48(3 \mathrm{H}, \mathrm{d}, J=6.5 \mathrm{~Hz}), 3.19(2 \mathrm{H}, \mathrm{d}, J=9.0 \mathrm{~Hz}), 3.44(1 \mathrm{H}, \mathrm{dd}, J=2.5$ and $7.5 \mathrm{~Hz}), 5.23(1 \mathrm{H}$, d, $J=14.0 \mathrm{~Hz}), 5.25(4 \mathrm{H}, \mathrm{s}), 5.42(1 \mathrm{H}, \mathrm{d}, J=14.0 \mathrm{~Hz}), 7.47(2 \mathrm{H}, \mathrm{d}, J=8.5 \mathrm{~Hz}), 7.52(2 \mathrm{H}, \mathrm{d}, J=8.5 \mathrm{~Hz})$, $7.60(2 \mathrm{H}, \mathrm{d}, J=8.5 \mathrm{~Hz}), 8.16(4 \mathrm{H}, \mathrm{d}, J=8.5 \mathrm{~Hz}), 8.19(2 \mathrm{H}, \mathrm{d}, J=8.5 \mathrm{~Hz})$.

$(5 R, 6 S)-2-[(3 S, 5 S)-(5-D i m e t h y l a m i n o c a r b o n y 1)$ pyrrolidin-3-ylthio]-6-[(R)-1-hydroxyethyl]carbapen-2-em-3-carboxylic Acid (1a)

A mixture of $26 \mathrm{a}(4.0 \mathrm{~g}, 4.64 \mathrm{mmol})$ and $10 \%$ Pd-C $(4.8 \mathrm{~g})$ in THF $(300 \mathrm{ml})$, EtOH $(48 \mathrm{ml})$ and $0.1 \mathrm{~m}$ MOPS buffer $(300 \mathrm{ml}$, $\mathrm{pH} 7.0)$ was stirred under hydrogen atmosphere for 5 hours at room temperature. The catalyst was filtered off and washed with THF $(100 \mathrm{ml})$ and $0.1 \mathrm{M}$ MOPS buffer $(50 \mathrm{ml})$ successively. The filtrate and washings were diluted with EtOAc $(50 \mathrm{ml})$ and the separated organic layer was re-extracted with $0.1 \mathrm{M}$ MOPS buffer $(50 \mathrm{ml})$. The combined aqueous layer was concentrated briefly to remove any residual organic solvents in vacuo and then subjected to column chromatography on Diaion CHP-20P (Mitsubishi Chemical Industries, Ltd.) which was successively eluted with water and water containing $1 \sim 2 \%$ of THF. The fractions having UV absorption at $290 \mathrm{~nm}$ were combined and lyophilized to give $1 \mathrm{a}(181 \mathrm{mg}, 43 \%)$ : IR $(\mathrm{KBr}) \mathrm{cm}^{-1} 1755,1627 ;{ }^{1} \mathrm{H}$ NMR $\left(\mathrm{D}_{2} \mathrm{O}\right) \delta 1.25(3 \mathrm{H}, \mathrm{d}, J=6.5 \mathrm{~Hz}), 1.81 \sim 1.96$ $(1 \mathrm{H}, \mathrm{m}), 2.96(3 \mathrm{H}, \mathrm{s}), 3.03(3 \mathrm{H}, \mathrm{s}), 3.14 \sim 3.72(6 \mathrm{H}, \mathrm{m}), 3.90 \sim 4.26(3 \mathrm{H}, \mathrm{m}), 4.63(1 \mathrm{H}, \mathrm{t}, J=8.5 \mathrm{~Hz})$; UV $\lambda_{\max }^{\mathrm{H}_{2} \mathrm{O}} \mathrm{nm} 297$.

The following compounds $(1 \mathbf{b} \sim 1 \mathbf{k})$ were prepared from $26 \mathbf{b} \sim 26 \mathbf{k}$ as described for the preparation of 1a, respectively.

1b: IR $(\mathrm{KBr}) \mathrm{cm}^{-1} 1752,1687,1595 ;{ }^{1} \mathrm{H}$ NMR $\left(\mathrm{D}_{2} \mathrm{O}\right) \delta 1.24(3 \mathrm{H}, \mathrm{d}, J=6.5 \mathrm{~Hz}), 2.00 \sim 2.15(1 \mathrm{H}, \mathrm{m})$, $2.83 \sim 2.98(1 \mathrm{H}, \mathrm{m}), 3.17(2 \mathrm{H}, \mathrm{d}, J=9.0 \mathrm{~Hz}), 3.32 \sim 3.42(2 \mathrm{H}, \mathrm{m}), 3.71 \sim 3.80(1 \mathrm{H}, \mathrm{m}), 3.98(1 \mathrm{H}, \mathrm{m})$, $4.13 \sim 4.32(1 \mathrm{H}, \mathrm{m}), 4.41(1 \mathrm{H}, \mathrm{t}, J=8.5 \mathrm{~Hz}) ; \mathrm{UV} \lambda_{\max }^{\mathrm{H}_{2} \mathrm{O}} \mathrm{nm} 297$.

1c: IR (KBr) cm ${ }^{-1} 1755,1635,1590 ;{ }^{1} \mathrm{H}$ NMR $\left(\mathrm{D}_{2} \mathrm{O}\right) \delta 0.88(3 \mathrm{H}, \mathrm{t}, J=7.0 \mathrm{~Hz}), 1.26(3 \mathrm{H}, \mathrm{d}, J=6.5 \mathrm{~Hz})$, $1.91(1 \mathrm{H}, \mathrm{m}), 2.94(3 \mathrm{H} \times 1 / 3, \mathrm{~s}), 3.02(3 \mathrm{H} \times 2 / 3, \mathrm{~s}) ; \mathrm{UV} \lambda_{\max }^{\mathrm{H}_{2} \mathrm{O}} \mathrm{nm} 297$.

1d: IR (KBr) cm ${ }^{-1} 1755,1630,1600,1440 ;{ }^{1} \mathrm{H}$ NMR $\left(\mathrm{D}_{2} \mathrm{O}\right) \delta 1.26(3 \mathrm{H}, \mathrm{d}, J=6.5 \mathrm{~Hz}), 2.34(2 \mathrm{H}, \mathrm{m})$, $3.36(1 \mathrm{H}, \mathrm{dd}, J=3.5$ and $5.5 \mathrm{~Hz}), 3.84(1 \mathrm{H}, \mathrm{m}) ; \mathrm{UV} \lambda_{\max }^{\mathrm{H}_{2} \mathrm{O}} \mathrm{nm} 298$.

1e: IR $(\mathrm{KBr}) \mathrm{cm}^{-1} 1750,1620 ;{ }^{1} \mathrm{H}$ NMR $\left(\mathrm{D}_{2} \mathrm{O}\right) \delta 1.27(3 \mathrm{H}, \mathrm{d}, J=6.0 \mathrm{~Hz}), 1.83(4 \mathrm{H}, \mathrm{t}, J=7.0 \mathrm{~Hz})$, $1.94 \sim 2.09(1 \mathrm{H}, \mathrm{m}), 2.42(4 \mathrm{H}, \mathrm{t}, J=7.0 \mathrm{~Hz}), 2.77 \sim 2.92(1 \mathrm{H}, \mathrm{m}), 3.11 \sim 3.42(5 \mathrm{H}, \mathrm{m}), 3.81 \sim 3.99(1 \mathrm{H}, \mathrm{m})$, $4.14 \sim 4.29(2 \mathrm{H}, \mathrm{m})$; UV $\lambda_{\max }^{\mathrm{H}_{2} \mathrm{O}} \mathrm{nm} 298$.

1f: IR (KBr) cm ${ }^{-1} 1750,1630,1595 ;{ }^{1} \mathrm{H}$ NMR $\left(\mathrm{D}_{2} \mathrm{O}\right) \delta 1.27(3 \mathrm{H}, \mathrm{d}, J=6.5 \mathrm{~Hz}), 1.85 \sim 2.00(1 \mathrm{H}, \mathrm{m})$, $3.20(1 \mathrm{H}, \mathrm{dd}, J=5.0$ and $9.0 \mathrm{~Hz})$; UV $\lambda_{\max }^{\mathrm{H}_{2} \mathrm{O}} \mathrm{nm} 297$.

1g: IR (KBr) cm ${ }^{-1} 1755,1640,1595,1450 ;{ }^{1} \mathrm{H}$ NMR $\left(\mathrm{D}_{2} \mathrm{O}\right) \delta 1.26(3 \mathrm{H}, \mathrm{d}, J=6.5 \mathrm{~Hz}), 3.18(1 \mathrm{H}, \mathrm{dd}$, $J=2.0$ and $9.0 \mathrm{~Hz}), 3.77(1 \mathrm{H}, \mathrm{dd}, J=7.0$ and $12.0 \mathrm{~Hz}), 5.89(2 \mathrm{H}, \mathrm{br} \mathrm{s})$; UV $\lambda_{\max }^{\mathrm{H}_{2} \mathrm{O}} \mathrm{nm} 298$.

1h: IR $(\mathrm{KBr}) \mathrm{cm}^{-1} 1750,1625,1590 ;{ }^{1} \mathrm{H}$ NMR $\left(\mathrm{D}_{2} \mathrm{O}\right) \delta 1.27(3 \mathrm{H}, \mathrm{d}, J=6.5 \mathrm{~Hz}), 1.74(1 \mathrm{H}, \mathrm{m}), 2.97$ $(3 \mathrm{H} \times 1 / 3, \mathrm{~s}), 3.10(3 \mathrm{H} \times 2 / 3, \mathrm{~s}), 4.20(2 \mathrm{H}, \mathrm{dd}, J=6.0$ and $12.0 \mathrm{~Hz}), 4.33(1 \mathrm{H}, \mathrm{q}, J=8.5 \mathrm{~Hz})$; UV $\lambda_{\max }^{\mathrm{H} 2 \mathrm{O}} \mathrm{nm} 297$.

1i: $\operatorname{IR}(\mathrm{KBr}) \mathrm{cm}^{-1} 1750,1680,1590,1480 ;{ }^{1} \mathrm{H}$ NMR $\left(\mathrm{D}_{2} \mathrm{O}\right) \delta 1.26(3 \mathrm{H}, \mathrm{d}, J=6.5 \mathrm{~Hz}), 2.73(3 \mathrm{H}, \mathrm{s})$, $3.09(3 \mathrm{H}, \mathrm{s}), 3.39(1 \mathrm{H}, \mathrm{q}, J=2.5 \mathrm{~Hz}) ; \mathrm{UV} \lambda_{\max }^{\mathrm{H}_{2} \mathrm{O}} \mathrm{nm} 298,286,237$.

1j: IR $(\mathrm{KBr}) \mathrm{cm}^{-1} 1750,1640,1585 ;{ }^{1} \mathrm{H}$ NMR $\left(\mathrm{D}_{2} \mathrm{O}\right) \delta 1.26(3 \mathrm{H}, \mathrm{d}, J=6.5 \mathrm{~Hz}), 1.95(1 \mathrm{H}, \mathrm{m}), 3.20$ $(1 \mathrm{H}, \mathrm{dd}, J=4.0$ and $9.0 \mathrm{~Hz}), 3.37(1 \mathrm{H}, \mathrm{dd}, J=2.5$ and $6.0 \mathrm{~Hz}), 8.32(1 \mathrm{H}, \mathrm{dd}, J=1.5$ and $5.0 \mathrm{~Hz}), 8.60(1 \mathrm{H}$, d, $J=2.0 \mathrm{~Hz}$ ); UV $\lambda_{\max }^{\mathrm{H}_{2} \mathrm{O}} \mathrm{nm} 300$.

1k: IR (KBr) cm ${ }^{-1} 1752,1650,1590 ;{ }^{1} \mathrm{H}$ NMR $\left(\mathrm{D}_{2} \mathrm{O}\right) \delta 1.26(3 \mathrm{H}, \mathrm{d}, J=6.5 \mathrm{~Hz}), 2.71(3 \mathrm{H}, \mathrm{s}), 2.93$ $(1 \mathrm{H}, \mathrm{q}, J=7.5 \mathrm{~Hz}), 3.88(2 \mathrm{H}, \mathrm{s}) ; \mathrm{UV} \lambda_{\max }^{\mathrm{H}_{2} \mathrm{O}} \mathrm{nm} 300$.

The following stereoisomers of $\mathrm{C}-2$ side chain $(\mathbf{2 a}, \mathbf{2 b}, \mathbf{3 a}, \mathbf{3 b}, \mathbf{4 a}$ and $\mathbf{4 b})$ were prepared from $29 \mathbf{a}$, $29 \mathrm{~b}, 30 \mathrm{a}, 30 \mathrm{~b}, 31 \mathrm{a}$ and $31 \mathrm{~b}$ as described for the preparation of $1 \mathrm{a}$, respectively.

2a: IR (KBr) cm ${ }^{-1} 1750,1630,1590 ;{ }^{1} \mathrm{H}$ NMR $\left(\mathrm{D}_{2} \mathrm{O}\right) \delta 1.27(3 \mathrm{H}, \mathrm{d}, J=6.5 \mathrm{~Hz}), 2.20 \sim 2.35(2 \mathrm{H}, \mathrm{m})$, $2.94(3 \mathrm{H}, \mathrm{s}), 3.06(3 \mathrm{H}, \mathrm{s}), 3.40(1 \mathrm{H}, \mathrm{dd}, J=2.5$ and $6.0 \mathrm{~Hz}), 3.56(1 \mathrm{H}, \mathrm{dd}, J=6.0$ and $12.0 \mathrm{~Hz}), 3.80(1 \mathrm{H}$, $\mathrm{m}), 4.43(1 \mathrm{H}, \mathrm{t}, J=8.0 \mathrm{~Hz})$ : UV $\lambda_{\max }^{\mathrm{H}_{2} \mathrm{O}} \mathrm{nm} 297$. 
2b: ${ }^{1} \mathrm{H}$ NMR $\left(\mathrm{D}_{2} \mathrm{O}\right) \delta 1.25(3 \mathrm{H}, \mathrm{d}, J=6.5 \mathrm{~Hz}), 2.36 \sim 2.44(2 \mathrm{H}, \mathrm{m}), 3.39(1 \mathrm{H}, \mathrm{dd}, J=3.0$ and $6.0 \mathrm{~Hz})$, $4.35(1 \mathrm{H}, \mathrm{t}, J=8.0 \mathrm{~Hz})$; UV $\lambda_{\max }^{\mathrm{H}_{2} \mathrm{O}} \mathrm{nm} 298$.

3a: IR (KBr) cm ${ }^{-1} 1755,1645,1600 ;{ }^{1} \mathrm{H}$ NMR $\left(\mathrm{D}_{2} \mathrm{O}\right) \delta 1.27(3 \mathrm{H}, \mathrm{d}, J=6.5 \mathrm{~Hz}), 1.90 \sim 2.10(1 \mathrm{H}, \mathrm{m})$, $2.96(3 \mathrm{H}, \mathrm{s}), 3.04(3 \mathrm{H}, \mathrm{s}), 3.71(1 \mathrm{H}, \mathrm{dd}, J=7.0$ and $12.5 \mathrm{~Hz})$; $\mathrm{UV} \lambda_{\max }^{\mathrm{H}_{2} \mathrm{O}} \mathrm{nm} 297$.

3b: ${ }^{1} \mathrm{H}$ NMR $\left(\mathrm{D}_{2} \mathrm{O}\right) \delta 1.25(3 \mathrm{H}, \mathrm{d}, J=6.5 \mathrm{~Hz}), 2.36 \sim 2.46(2 \mathrm{H}, \mathrm{m}), 3.39(1 \mathrm{H}, \mathrm{dd}, J=2.5$ and $6.0 \mathrm{~Hz})$, $3.64(1 \mathrm{H}, \mathrm{dd}, J=6.0$ and $12.0 \mathrm{~Hz}), 4.39(1 \mathrm{H}, \mathrm{t}, J=8.0 \mathrm{~Hz}) ; \mathrm{UV} \lambda_{\max }^{\mathrm{H}_{2} \mathrm{O}} \mathrm{nm} 297$.

4a: IR (KBr) cm ${ }^{-1} 1750,1630,1590 ;{ }^{1} \mathrm{H} \mathrm{NMR}\left(\mathrm{D}_{2} \mathrm{O}\right) \delta 1.27(3 \mathrm{H}, \mathrm{d}, J=6.5 \mathrm{~Hz}), 2.29(2 \mathrm{H}, \mathrm{t}, J=7.5 \mathrm{~Hz})$, $2.95(3 \mathrm{H}, \mathrm{s}), 3.07(3 \mathrm{H}, \mathrm{s}), 3.39(1 \mathrm{H}, \mathrm{m}), 3.57(1 \mathrm{H}, \mathrm{dd}, J=6.0$ and $12.0 \mathrm{~Hz}), 3.83(1 \mathrm{H}, \mathrm{m}), 4.48(1 \mathrm{H}, \mathrm{t}$, $J=8.0 \mathrm{~Hz}) ; \mathrm{UV} \lambda_{\max }^{\mathrm{H}_{2} \mathrm{O}} \mathrm{nm} 297$.

4b: ${ }^{1} \mathrm{H}$ NMR $\left(\mathrm{D}_{2} \mathrm{O}\right) \delta 1.25(3 \mathrm{H}, \mathrm{d}, J=6.5 \mathrm{~Hz}), 2.05 \sim 2.23(2 \mathrm{H}, \mathrm{m}), 3.73(1 \mathrm{H}, \mathrm{dd}, J=7.0$ and $12.0 \mathrm{~Hz})$, $4.13 \sim 4.25(2 \mathrm{H}, \mathrm{m}), 4.40(1 \mathrm{H}, \mathrm{t}, J=8.0 \mathrm{~Hz}) ; \mathrm{UV} \lambda_{\max }^{\mathrm{H}_{\mathbf{2}} \mathrm{O}} \mathrm{nm} 297$.

PNB (1 $R, 5 S, 6 S)$-2-[(3S,5S)-(5-Dimethylaminocarbonyl-1-p-nitrobenzyloxycarbonyl)pyrrolidin-3ylthio]-6-[(R)-1-hydroxyethyl]-1-methylcarbapen-2-em-3-carboxylate (32a)

To a solution of PNB $(1 R, 5 R, 6 S)$-[( $R)$-1-hydroxyethyl]-2-oxocarbapenam-3-carboxylate (27) (1.86 g, $5.13 \mathrm{mmol})$ and diisopropylethylamine $(795 \mathrm{mg}, 6.15 \mathrm{mmol})$ in $\mathrm{CH}_{3} \mathrm{CN}(16 \mathrm{ml})$ was added diphenyl chlorophosphate $(1.65 \mathrm{~g}, 6.15 \mathrm{mmol})$ at $0 \sim 5^{\circ} \mathrm{C}$ under nitrogen atmosphere. After stirring for 1 hour, the reaction mixture was cooled to $-30^{\circ} \mathrm{C}$. Diisopropylethylamine $(795 \mathrm{mg}, 6.15 \mathrm{mmol})$ and then mercaptan (13a) $(2.17 \mathrm{~g}, 6.15 \mathrm{mmol})$ was added to this mixture at $-30 \sim-20^{\circ} \mathrm{C}$ and followed by stirring for 1 hour at the same temperature. The reaction mixture was diluted with EtOAc, washed with brine and dried over $\mathrm{MgSO}_{4}$. Evaporation of the solvents in vacuo gave an oily residue which was purified by silica gel column chromatography $\left(\right.$ EtOAc $\left.-\left(\mathrm{CH}_{3}\right)_{2} \mathrm{CO}, 4: 1\right)$ to give $32 \mathrm{a}(2.5 \mathrm{~g}, 70 \%)$ as a pale yellow powder: IR (neat) $\mathrm{cm}^{-1} 1760,1705,1645,1520 ;{ }^{1} \mathrm{H}$ NMR $\left(\mathrm{CDCl}_{3}\right) \delta 1.30(3 \mathrm{H}, \mathrm{d}, J=7.0 \mathrm{~Hz}), 1.35(3 \mathrm{H}$, d, $J=6.5 \mathrm{~Hz}), 2.99(3 \mathrm{H}, \mathrm{s}), 3.02(3 \mathrm{H}, \mathrm{d}, J=15.0 \mathrm{~Hz}), 5.20(1 \mathrm{H}, \mathrm{d}, J=14.0 \mathrm{~Hz}), 5.21(2 \mathrm{H}, \mathrm{s}), 5.43(1 \mathrm{H}, \mathrm{d}$, $J=14.0 \mathrm{~Hz}), 7.51(2 \mathrm{H}, \mathrm{d}, J=8.5 \mathrm{~Hz}), 7.62(2 \mathrm{H}, \mathrm{d}, J=8.5 \mathrm{~Hz}), 8.20(4 \mathrm{H}, \mathrm{d}, J=8.5 \mathrm{~Hz}) ;$ FD-MS $m / z 698$ $(\mathrm{M}+\mathrm{H})$.

PNB (1R,5S,6S)-6-[(R)-1-hydroxyethyl]-2-[(3S,5S)-(5-pyrrolidinylcarbonyl-1-p-nitrobenzyloxycarbonyl)pyrrolidin-3-ylthio]-1-methylcarbapen-2-em-3-carboxylate (32e) was prepared from 27 and 13e as described above for the preparation of 32a: IR (neat) $\mathrm{cm}^{-1} 1760,1710,1640,1525 ;{ }^{1} \mathrm{H} \mathrm{NMR}\left(\mathrm{CDCl}_{3}\right)$ $\delta 1.30(3 \mathrm{H}, \mathrm{d}, J=7.0 \mathrm{~Hz}), 1.34(3 \mathrm{H}, \mathrm{d}, J=6.5 \mathrm{~Hz}), 5.20(1 \mathrm{H}, \mathrm{d}, J=14.0 \mathrm{~Hz}), 5.21(2 \mathrm{H}, \mathrm{s}), 5.44(1 \mathrm{H}, \mathrm{d}$, $J=14.0 \mathrm{~Hz}), 7.50(2 \mathrm{H}, \mathrm{d}, J=8.5 \mathrm{~Hz}), 7.64(2 \mathrm{H}, \mathrm{d}, J=8.5 \mathrm{~Hz}), 8.20(4 \mathrm{H}, \mathrm{d}, J=8.5 \mathrm{~Hz})$.

$(1 R, 5 S, 6 S)-2-[(3 S, 5 S)$-(5-Dimethylaminocarbonyl)pyrrolidin-3-ylthio]-6-[(R)-1-hydroxyethyl]1-methylcarbapen-2-em-3-carboxylic Acid (5a)

A mixture of $32 \mathrm{a}(2.0 \mathrm{~g}, 2.87 \mathrm{mmol})$ and $10 \% \mathrm{Pd}-\mathrm{C}(3.0 \mathrm{~g})$ in THF $(15 \mathrm{ml})$ and $0.6 \mathrm{M}$ MOPS buffer $(30 \mathrm{ml}, \mathrm{pH} 7.0)$ was stirred under hydrogen atmosphere for 3 hours at room temperature. The catalyst was filtered off and washed with $0.1 \mathrm{M}$ MOPS buffer $(5 \mathrm{ml})$. THF was evaporated in vacuo and the residual solution was washed with $\mathrm{CH}_{2} \mathrm{Cl}_{2}$. The separated aqueous layer was concentrated briefly to remove any residual organic solvents in vacuo and then subjected to column chromatography on Diaion CHP-20P which was successively eluted with water and water containing $1 \%$ of THF. The fractions having UV absorption at $290 \mathrm{~nm}$ were combined and lyophilized to give $5 \mathrm{a}(600 \mathrm{mg}, 61 \%)$ as a colorless powder: IR $(\mathrm{KBr}) \mathrm{cm}^{-1} 3400,1748,1650 ;{ }^{1} \mathrm{H}$ NMR $\left(\mathrm{D}_{2} \mathrm{O}\right) \delta 1.21(3 \mathrm{H}, \mathrm{d}, J=7.0 \mathrm{~Hz}), 1.28(3 \mathrm{H}, \mathrm{d}, J=6.5 \mathrm{~Hz}), 1.97$ $(1 \mathrm{H}, \mathrm{m}), 2.99(3 \mathrm{H}, \mathrm{s}), 3.06(3 \mathrm{H}, \mathrm{s}), 3.38(1 \mathrm{H}, \mathrm{m}), 3.46 \sim 3.50(2 \mathrm{H}, \mathrm{m}), 3.76(1 \mathrm{H}, \mathrm{dd}, J=6.5$ and $12.0 \mathrm{~Hz})$, $4.05(1 \mathrm{H}, \mathrm{m}), 4.21 \sim 4.29(2 \mathrm{H}, \mathrm{m})$; UV $\lambda_{\max }^{\mathrm{H}_{2} \mathrm{O}} \mathrm{nm} 295$.

$(1 R, 5 S, 6 S)-6-[(R)-1-$ Hyd roxyethyl]-2-[(3S, 5S)-(5-pyrrolidinylcarbonyl)pyrrolidin-3ylthiol-1-methylcarbapen-2-em-3-carboxylic acid (5e) was prepared from 32e as described above for the preparation of 5a: IR $(\mathrm{KBr}) \mathrm{cm}^{-1} 3400,1753,1640,1595 ;{ }^{1} \mathrm{H}$ NMR $\left(\mathrm{D}_{2} \mathrm{O}\right) \delta 1.20(3 \mathrm{H}, \mathrm{d}, J=7.0 \mathrm{~Hz})$, $1.28(3 \mathrm{H}, \mathrm{d}, J=6.5 \mathrm{~Hz}), 1.95(6 \mathrm{H}, \mathrm{m}), 3.46(6 \mathrm{H}, \mathrm{m}), 3.72(1 \mathrm{H}, \mathrm{dd}, J=6.5$ and $12.0 \mathrm{~Hz}), 4.02(1 \mathrm{H}, \mathrm{m})$; UV $\lambda_{\max }^{\mathrm{H}_{2} \mathrm{O}} \mathrm{nm} 297$.

PNB (1S,5S,6S)-2-[(3S,5S)-(5-Dimethylaminocarbonyl-1-p-nitrobenzyloxycarbonyl)pyrrolidin-3ylthio]-6-[( $R)$-1-hydroxyethyl]-1-methylcarbapen-2-em-3-carboxylate (33a)

To a solution of PNB $(1 S, 5 R, 6 S)$-[(R)-1-hydroxyethyl]-2-oxo-1-methylcarbapenam-3-carboxylate (28) 
$(1.21 \mathrm{~g}, 3.34 \mathrm{mmol})$, diisopropylethylamine $(452 \mathrm{mg}, 3.5 \mathrm{mmol})$ and 4-dimethylaminopyridine (20 $\mathrm{mg}$, $0.17 \mathrm{mmol})$ in $\mathrm{CH}_{3} \mathrm{CN}(15 \mathrm{ml})$ was added diphenyl chlorophosphate $(0.94 \mathrm{~g}, 3.5 \mathrm{mmol})$ at $-10 \sim-5^{\circ} \mathrm{C}$ under nitrogen atmosphere. After stirring for 20 minutes, diisopropylethylamine $(430 \mathrm{mg}, 3.34 \mathrm{mmol})$ and then mercaptan $(13 \mathrm{a}, 1.18 \mathrm{~g}, 3.34 \mathrm{mmol})$ were added to this mixture at the same temperature and stirred for 1 hour. The reaction mixture was diluted with EtOAc, washed with brine and dried over $\mathrm{MgSO}_{4}$. Evaporation of the solvents in vacuo gave an oily residue which was purified by silica gel column chromatography (EtOAc- $\left.\left(\mathrm{CH}_{3}\right)_{2} \mathrm{CO}, 4: 1\right)$ to give $33 \mathrm{a}(1.16 \mathrm{~g}, 50 \%)$ as a pale yellow powder: IR $\left(\mathrm{CHCl}_{3}\right)$ $\mathrm{cm}^{-1} 1775,1700,1650,1520 ;{ }^{1} \mathrm{H}$ NMR $\left(\mathrm{CDCl}_{3}\right) \delta 1.34(3 \mathrm{H}, \mathrm{d}, J=6.0 \mathrm{~Hz}), 1.36(3 \mathrm{H}, \mathrm{d}, J=7.0 \mathrm{~Hz}), 3.00$ $(3 \mathrm{H}, \mathrm{s}), 3.16(3 \mathrm{H}, \mathrm{s}), 5.26(1 \mathrm{H}, \mathrm{d}, J=14.0 \mathrm{~Hz}), 5.43(1 \mathrm{H}, \mathrm{d}, J=14.0 \mathrm{~Hz}), 7.47(2 \mathrm{H}, \mathrm{d}, J=9.0 \mathrm{~Hz}), 7.64(2 \mathrm{H}$, d, $J=9.0 \mathrm{~Hz}), 8.20(4 \mathrm{H}, \mathrm{d}, J=9.0 \mathrm{~Hz})$.

$(1 S, 5 S, 6 S)-2-[(3 S, 5 S)-(5-D i m e t h y l a m i n o c a r b o n y l) p y r r o l i d i n-3-y 1 t h i o]-6-[(R)-1-h y d r o x y e t h y 1]-$ 1-methylcarbapen-2-em-3-carboxylic Acid (6a)

A mixture of $33 \mathrm{a}(1.0 \mathrm{~g}, 1.43 \mathrm{mmol})$ and $10 \% \mathrm{Pd}-\mathrm{C}(1.2 \mathrm{~g})$ in THF $(15 \mathrm{ml})$ and $0.6 \mathrm{M}$ MOPS buffer $(10 \mathrm{ml}, \mathrm{pH} 7.0)$ was stirred under hydrogen atmosphere for 2.5 hours at room temperature. The same work-up as described for the preparation of 5 a was carried out to give $\mathbf{6 a}(205 \mathrm{mg}, 37 \%)$ as a colorless powder; ${ }^{1} \mathrm{H}$ NMR $\left(\mathrm{D}_{2} \mathrm{O}\right) \delta 1.26(3 \mathrm{H}, \mathrm{d}, J=6.5 \mathrm{~Hz}), 1.28(3 \mathrm{H}, \mathrm{d}, J=6.5 \mathrm{~Hz}), 1.95(1 \mathrm{H}, \mathrm{m}), 2.96(3 \mathrm{H}, \mathrm{s})$, $3.02(3 \mathrm{H}, \mathrm{s}), 3.27(1 \mathrm{H}, \mathrm{m}), 3.46(1 \mathrm{H}, \mathrm{dd}, J=3.0$ and $6.0 \mathrm{~Hz}), 3.76(1 \mathrm{H}, \mathrm{dd}, J=3.0$ and $8.0 \mathrm{~Hz}), 4.06(1 \mathrm{H}$, $\mathrm{m}), 4.21(1 \mathrm{H}, \mathrm{m}) ; \mathrm{UV} \lambda_{\max }^{\mathrm{H}_{2} \mathrm{O}} \mathrm{nm} 295$.

Measurement of In Vitro Antibacterial Activity

MICs were determined by the 2-fold agar dilution method using Sensitivity Test Agar (Nissui). An appropriate dilution $\left(10^{6} \mathrm{cells} / \mathrm{ml}\right)$ of a fresh overnight culture of the test organism was prepared as an inoculum. The inoculated plates were incubated at $37^{\circ} \mathrm{C}$ for 18 hours, and the MIC $(\mu \mathrm{g} / \mathrm{ml})$ which was the lowest concentration of the test compound that inhibited the development of visible growth of the test microorganism, was determined.

Stability Test of Carbapenem Compounds to DHP-I

The DHP-I stability was determined by spectrophotometric method in a spectrophotometer controlled at $37^{\circ} \mathrm{C}$. Renal DHP-I was partially purified from swine kidney by CAMBELL's method ${ }^{12)}$. The apparent $\mathrm{T}_{1 / 2}$ (minutes) of enzyme-catalyzed hydrolysis of the test compound $(200 \mu \mathrm{M})$ was measured in the presence of the limited amount of enzyme by the decrease in absorbance at the wavelength around $300 \mathrm{~nm}$ in $50 \mathrm{~mm}$ MOPS buffer ( $\mathrm{pH} 7.2$ ), at which the test compound absorbed maximally.

Acknowledgments

We would like to express our thanks to Dr. T. OKuDA for helpful discussion.

\section{References}

1) Kahan, J. S.; F. M. Kahan, R. Goggelman, S. A. Currie, M. Jackson, E. O. Stapley, T. W. Miller, A. K. Miller, D. Hendlin, S. Mochales, S. Hernandez, H. B. Woodruff \& J. Birnbaum: Thienamycin, a new $\beta$-lactam antibiotic. I. Discovery, taxonomy, isolation and physical properties. J. Antibiotics 32: 1 12, 1979

2) Kropp, H.; J. G. Sundelof, R. HAJdu \& F. M. Kahan: Metabolism of thienamycin and related carbapenem antibiotics by the renal dipeptidase, dehydropeptidase-I. Antimicrob. Agents Chemother. 22: 62 70, 1982

3) Sunagawa, M.; H. Matsumura, T. Inoue, M. Fukasawa \& M. Kato: SM-7338, a new carbapenem antibiotic: Structure-activity relations and physicochemical properties. Program and Abstracts of the 27th Intersci. Conf. on Antimicrob. Agents Chemother., No. 752, p. 228, New York, Oct. 4 7, 1987

4) Mitsunobu, O.: The use of diethyl azodicarboxylate and triphenylphosphine in synthesis and transformation of natural products. Synthesis 1981: $1 \sim 28,1981$

5) Stewart, F. H. C.: The $p$-methoxybenzyl ester group in peptide synthesis. Aust. J. Chem. 21: 2543 2550, 1968

6) Danneels, D.; M. Anteunis, L. VAn ACKeR \& D. TAVernier: Preparation of the laevorotatory trans(4S,6S)-4,6-dimethyl-1,3-dithiane and trans-(4S,6S)-4,6-dimethyl-1,3-oxathiane. An internal displacement of a secondary sulphonate leading to a cyclic thioacetal. Tetrahedron 31: $327 \sim 331,1975$

7) Salzmann, T. N.; R. W. Ratcliffe, B. G. Christensen \& F. A. Bouffard: A stereocontrolled synthesis of 
(+)-thienamycin. J. Am. Chem. Soc. 102: $6161 \sim 6163,1980$

8) Kametani, T; S. Huang, T. Nagahara \& M. Ihara: An alternative total synthesis of ( \pm )-thienamycin. Heterocycles 14: 1305 1308, 1980

9) SHH, D. H.; F. BAKER, L. CAMA \& B. G. CHRISTENSEN: Synthetic carbapenem antibiotics I. 1- $\beta$-Methylcarbapenem. Heterocycles 21: $29 \sim 40,1984$

10) ShiH, D. H.; L. Cama \& B. G. Christensen: Synthetic carbapenem antibiotics III. 1-Methyl thienamycin. Tetrahedron Lett. 26: $587 \sim 590,1985$

11) Andrus, A.; F. Baker, F. A. Bouffard, L. D. Cama, B. G. Christensen, R. N. Guthikonda, J. V. Heck, D. B. R. Johnston, W. J. Leanza, R. W. Ratcliffe, T. N. Salzmann, S. M. Schmitt, D. H. Shih, N. V. Shah, K. J. WILDONGER \& R. R. WILKERNING: Structure-activity relationships among some totally synthetic carbapenems. In Recent Advances in the Chemistry of $\beta$-Lactam Antibiotics. Eds., A. G. Brown \& S. M. ROBERTS, pp. 86 99, The Royal Society of Chemistry, 1985

12) Cambell, B. J.: Renal dipeptidase. Methods Enzymol. 19: 722 729, 1970 